\title{
Effect of Doppler Radial Velocity Data Assimilation on the Simulation of a Typhoon Approaching Taiwan: A Case Study of Typhoon Aere (2004)
}

\author{
Hsin-Hung Lin $^{1}$, Pay-Liam Lin ${ }^{1, *}$, Qingnong Xiao ${ }^{2}$, and Ying-Hwa Kuo ${ }^{2}$ \\ ${ }^{I}$ Institute of Atmospheric Physics, National Central University, Jhongli, Taiwan \\ ${ }^{2}$ National Center for Atmospheric Research, Boulder, Colorado, USA
}

Received 30 April 2009, accepted 8 October 2010

\begin{abstract}
Compared to conventional data, radar observations have an advantage of high spatial and temporal resolutions, and Doppler radars are capable of capturing detailed characteristics of flow fields, including typhoon circulation. In this study, the possible improvement of short-term typhoon predictions near Taiwan, particularly with regard to related rainfall forecasts over the mountainous island, using Doppler radial wind observations is explored. The case of Typhoon Aere (2004) was chosen for study, and a series of experiments were carried out using the Penn State University/National Center for Atmospheric Research (PSU/NCAR) Mesoscale Model Version 5 (MM5) with its three-dimensional variational (3D-VAR) data assimilation system.

The results show that once the Doppler radial velocities were assimilated into the model, the typhoon's circulation intensified within one hour. However, when Typhoon Aere approached from the east and only the western half of its core area could be observed by the radar, the assimilation caused the typhoon to deflect southward due to the incomplete and uneven data coverage. In another experiment in which Doppler radar data assimilation did not start until Typhoon Aere moved closer, such that its entire core region could be observed. A similar track deflection was avoided. Overall, the assimilation of Doppler radial velocity data reduced the intensity error (in wind speed) by about $25 \%$. Furthermore, the improvements in location, intensity, and circulation structure of Typhoon Aere lead to better rainfall prediction over the island of Taiwan.
\end{abstract}

Key words: Doppler radial velocity, Data assimilation, 3D-VAR

Citation: Lin, H. H., P. L. Lin, Q. Xiao, and Y. H. Kuo, 2011: Effect of Doppler radial velocity data assimilation on the simulation of a typhoon approaching Taiwan: A case study of Typhoon Aere (2004). Terr. Atmos. Ocean. Sci., 22, 325-345, doi: 10.3319/TAO.2010.10.08.01(A)

\section{INTRODUCTION}

Yearly typhoons are the most disastrous weather systems affecting Taiwan. On average, three to four typhoons strike Taiwan annually, causing great loss of life and damage to the economy. A typhoon track forecast with wind and rain distribution is very important for disaster mitigation. However, the complicated topography of the Central Mountain Range (CMR) in Taiwan makes typhoon prediction a challenging task, especially when typhoon circulation interacts with the CMR.

The difficulties involved in predicting typhoons near Taiwan have been discussed extensively in the literature. Wu and Kuo (1999) pointed out that the major problems of typhoon prediction are caused by: (1) inadequate observa-

\footnotetext{
* Corresponding author

E-mail:tliam@atm.ncu.edu.tw
}

tions; (2) insufficient model resolution; and (3) the complicated influence of the CMR on airflow. Wu et al. (2006) showed that the wind field is critical for maintaining the correct initial vortex structure through Observation Systems Simulation Experiments (OSSEs) and demonstrated the importance of tropical cyclone initialization. Since the traditional data over the ocean is sparse, additional observations from satellite, dropsonde, and Doppler radar become important. Those data can be used to increase observations in data void regions and can be assimilated into models to improve typhoon simulations and forecasts. Chen (2007) studied the impacts of remote sensing data from the Special Sensor Microwave Imager (SSM/I) and the Quick Scatterometer (QuikSCAT) on the simulations of the Hurricane Isidore (2002). She found that the assimilation of SSM/I and QuikSCAT winds can improve typhoon predictions. 
This assimilation can reduce more than half the errors in sea level pressure (SLP) and the maximum low-level wind for the first 2 days' simulation. In addition, the assimilation of QuikSCAT wind vectors helped to correct the simulated storm position, especially the wind directions. Chen et al. (2009) developed a new nonlocal operator for the assimilation of the Global Positioning System Radio Occultation (GPS RO) refractivity in the Weather Research and Forecasting model variational data assimilation system (WRFVar) and applied this methodology to simulate a typhoon impinging on Taiwan. The GPS RO data assimilation was able to reduce typhoon track error on the first day of a 3-day prediction. The tropical cyclone track and intensity simulations were evaluated during the Dropwindsonde Observations for Typhoon Surveillance near Taiwan Region (DOTSTAR) program (Wu et al. 2007; Chou and Wu 2008) in 2004. Chou and $\mathrm{Wu}(2008)$ showed an average reduction in $6-72 \mathrm{~h}$ track errors by about $25 \%$ after assimilation of dropwindsonde data for 10 cases in the year 2004. The Doppler radar network coverage in Taiwan screens the whole island and its surrounding seas. The radar network can provide additional data to improve modelling of initial fields and simulations, especially for typhoon prediction. Jian (2003) used the MM5 numerical model coupled with the Local Analysis and Prediction System (LAPS-MM5) for assimilating local surface, sounding and radar data to improve the $3-6$ hour rainfall predictions.

Compared to conventional data, radar observations have the advantage of high spatial and temporal resolutions, and Doppler radars are capable of capturing detailed characteristics of flow fields, including the typhoon circulation. In addition, the high resolution radar observations can be used to retrieve three-dimensional mesoscale structures of dynamic and thermodynamic fields (via thermodynamic retrievals) within the typhoon. Various assimilation techniques have been developed recently for analyzing and retrieving the atmospheric structure from Doppler radar data. Sun and Crook $(1997,1998)$ developed a four dimensional variational data assimilation technique (4D-VAR) to ingest Doppler radar data into a numerical cloud model. However, 4D-VAR takes a very long time to adjust the background in assimilating time windows. Another assimilation technique is the ensemble Kalman filter (EnKF) method, which has a similar capability to the 4D-VAR analysis (Snyder and Zhang 2003; Zhang et al. 2004; Tong and Xue 2005; Xue et al. 2006). A dual-resolution data assimilation algorithm has been developed based on EnKF to reduce the computational cost with flow-dependent background error covariances estimated from a lower-resolution ensemble (Gao and Xue 2008). Compared to 4D-VAR and EnKF, 3D-VAR takes less computational time to adjust model background fields. Although 3D-VAR is not the best assimilation method for model prediction, it is more effective in the short-term forecast.
Some regional models and non-hydrostatic models were built with the 3D-VAR system used for radar data assimilation (Gao et al. 1999; Lindskog et al. 2004; Hu and Xue 2006; Montmerle and Faccani 2009). Xiao et al. (2005) developed a radar data assimilation method for MM5 and demonstrated that the method of radar wind data assimilation is useful for 6-h rainfall forecasts on a front. Xiao and Sun (2007) applied a multiple-radar data assimilation method of the WRF 3D-VAR to examine a real squall line case. Xiao et al. (2007) utilized radar radial velocity and radar reflectivity to probe their contributions to short-range quantitative precipitation forecasts (QPF) of typhoons. They found a positive impact, mainly on the first 3 -h of forecasting. Xiao et al. (2008) verified the benefit of Doppler radar data assimilation on operational forecasting for the Korean Meteorological Administration (KMA). Zhao et al. (2006) developed a three-and-half-dimensional variational data assimilation (3.5D-VAR) system for radar wind data to initialize the Navy's Coupled Ocean-Atmosphere Mesoscale Prediction System (COAMPS) model. Zhao and Jin (2008) improved the simulated hurricane intensity and structure by assimilating radar data into the COAMPS model using 3.5D-VAR. They revealed that the maximum of surface wind speed $\left(5 \mathrm{~m} \mathrm{~s}^{-1}\right)$ was increased in the first 5 -h forecasts. Precipitation forecasts along the path of the inner-core region during the hurricane land-fall show the most improvement. The results could be related to the enhanced dynamical structures in that region due to the Doppler wind data assimilation.

Typhoon Aere was a severe weather system that invaded Taiwan and generated heavy rainfall in excess of hundreds of millimetres on the windward side of the CMR. Numerous mud slide disasters occurred due to heavy rainfall in the higher mountain area. The typhoon left 24 people dead and 9 missing in the region. The economic losses were estimated to have been at least NT\$ 400 million. Improved methods to forecast the track and distribution of wind and rainfall of typhoons invading Taiwan are well worth study, with the eventual goal of enhancing the effectiveness of disaster mitigation.

Mesoscale precipitation patterns induced by typhoon circulation over complicated terrain are difficult to predict. Radar wind data assimilations are used to study possible improvements to this problem. Doppler radar wind assimilation in a typhoon prediction model has already demonstrated a certain improvement in more recent studies. However, this kind of typhoon prediction attempt in the Taiwan area is still very rare. The complicated topography of the island impedes accurate prediction of the typhoon track, structure and precipitation. Improving radar data assimilation algorithms and understanding their limitations are worth investigation. In this study, the potential improvement of short-term typhoon predictions near Taiwan, particularly the related rainfall forecasts over the mountainous island, using Doppler 
radial wind observations is explored. The case of Typhoon Aere (2004) is chosen for study, and a series of experiments are carried out using the Penn State University/National Center for Atmospheric Research (PSU/NCAR) Mesoscale Model Version 5 (MM5) with its three-dimensional variational (3D-VAR) data assimilation system.

This paper is organized as follows. The MM5 3D-VAR system used for the assimilation of Doppler radial velocities is discussed in section 2. Descriptions of Typhoon Aere, the model configuration, and experimental design are presented in section 3. Results of cycling assimilating experiments are presented in section 4 . Sensitivity tests are described in section 5 , and a brief summary is given in section 6 .

\section{3D-VAR DATA ASSIMILATION SYSTEM}

The MM5 3D-VAR system used here can assimilate both conventional and non-conventional data, such as the sounding data and Doppler radial velocity of weather radar. In the MM5 3D-VAR system, an optimal estimation of the true atmospheric state at the time of analysis is calculated by finding the iterative solution of a prescribed cost-function that can be expressed as

$$
\begin{aligned}
J(\mathbf{x})=J^{b}+J^{o} & =\frac{1}{2}\left(\mathbf{x}-\mathbf{x}^{b}\right)^{T} \mathbf{B}^{-1}\left(\mathbf{x}-\mathbf{x}^{b}\right) \\
& +\frac{1}{2}\left(\mathbf{y}-\mathbf{y}^{o}\right)^{T}(\mathbf{E}+\mathbf{F})^{-1}\left(\mathbf{y}-\mathbf{y}^{o}\right)
\end{aligned}
$$

where $\mathbf{B}, \mathbf{E}$, and $\mathbf{F}$ are the background, observation, and representative error covariance matrices, respectively (Barker et al. 2003). The representative error $\mathbf{F}$ is caused by the transformation of the operator from the model grid to observational space. The $3 \mathrm{D}-\mathrm{VAR}$ processes include minimization of $J(\mathbf{x})$ to search for the best atmospheric states.

Observations can be assimilated directly by minimizing the difference between model variables and observations, when the observational variables match the model variables. Indirect variables are assimilated by mapping model variables onto the observational space using observational operators. The observational operator for the Doppler radial velocity $\left(V_{r, i}\right)$ can be expressed as follows:

$$
V_{r, i}=u \frac{x-x_{i}}{r_{i}}+v \frac{y-y_{i}}{r_{i}}+\left(w-V_{T}\right) \frac{z-z_{i}}{r_{i}}
$$

where $u, v, w$ are model wind components in the $x, y, z$ directions, respectively. The variable $r$ is the distance from the radar location to the radial velocity observation point. $V_{T}$ is the terminal velocity of the precipitating particles and can be estimated from the numerical weather prediction model's rain water content. Model variables could be transferred to observational grid points through an observational operator. In order to assimilate Doppler velocity data, the re- gional MM5 3D-VAR system was modified to include vertical velocity increments. The balance equation for Doppler radial velocity assimilation is derived from the continuity equation, adiabatic thermodynamic equation, and hydrostatic relation. This balance equation is expressed as (Xiao et al. 2005)

$\gamma p \frac{\partial w}{\partial z}=-\gamma p \vec{\nabla} \cdot \vec{V}_{h}-\vec{V}_{h} \cdot \vec{\nabla} p+g \int_{z}^{\infty} \vec{\nabla} \cdot\left(\rho \vec{V}_{h}\right) d z$

where $w$ is vertical velocity, $\vec{V}_{h}$ is the vector of horizontal velocity, $\gamma$ is the ratio of specific heat capacities of air at a constant pressure to that at a constant volume. The symbol $p$ represents pressure, $\rho$ density, $z$ height, and $g$ the gravitational acceleration. The advantages of this method are the higher order approximation of the continuity equation and the efficient linkage between the dynamic and thermodynamic processes.

The observation error covariance matrix for the MM5 $3 \mathrm{D}-\mathrm{VAR}$ is derived from the observation errors. Observation errors of Doppler wind arise from several sources, such as contamination by ground clutter, spectrum broadening due to turbulence, and the spread of beam-width with distance. It is difficult to estimate real errors in the Doppler radial velocity for data assimilation. Xiao et al. (2005) considered that errors could be caused by the interpolation processes when transferring radar data from radar coordinates to Cartesian coordinates. They estimated the errors using the standard deviation for adjacent points in the interpolation, calculated through empirical rescaling. Montmerle and Faccani (2009) calculated the radar observation errors of Doppler velocity using an error-distance relation, and the observation error ranges from 1 to $3.4 \mathrm{~m} \mathrm{~s}^{-1}$ at $150 \mathrm{~km}$ from the radar. They suggested that increasing the distance from the target to the radar could increase observation errors because of radar beam broadening.

The radar signal is reflected by hydrometeor particles in the air. The terminal velocities of the different drops within a radar resolution volume associated with a larger drop size distribution inherit a broader Doppler spectrum width. Furthermore, as the terminal velocity component projected into the radial direction increases with the elevation angle, the observation errors increase with elevation due to spectrum broadening. The higher elevation from the surface increases the probability that more components from inhomogeneous motions of hydrometeor particles are projected to the radial direction of radar beam because of the drop size distribution and turbulence. These errors are indirectly taken into account by the observation error that depends linearly on the height of targets to the surface. In this assumption, the observation error ranges set 2 to $4 \mathrm{~m} \mathrm{~s}^{-1}$ from surface to $10 \mathrm{~km}$ height that are regulated to empirical ranges which are just slightly higher than the error ranges from Montmerle and Faccani (2009). 
Before assimilation of the Doppler radar data, the signal noise, ground clutter and sea clutter should be removed, and the Doppler velocity data also need to be unfolded. The MM5 3D-VAR requires radar observational data on the Cartesian coordinate plane for data assimilation. Therefore, the radar data are interpolated from polar coordinates to Cartesian coordinates. Since the radial resolution of radar data along each beam is $500 \mathrm{~m}$, and the model Cartesian horizontal grid distance is $4 \mathrm{~km}$, the interpolation scheme automatically has a thinning effect in near range of the radar site. This interpolation process will also reduce the small scale features that cannot be represented in the model analyses. The Doppler velocity was interpolated onto a $4 \mathrm{~km}$ horizontal and $0.5 \mathrm{~km}$ vertical Cartesian grid for 3D-VAR assimilation.

\section{ASSIMILATION EXPERIMENTS}

\subsection{Case Description}

Typhoon Aere was chosen for our case study. It was a severe weather system which caused heavy rainfall in the mountain area in the northern part of Taiwan. Typhoon Aere formed in the western Pacific Ocean at $14^{\circ} \mathrm{N}$ and $135^{\circ} \mathrm{E}$ on 20 August 2004, intensifying as it moved northwest toward northern Taiwan and passed by northern Taiwan within the observational range of the Doppler radar located on $\mathrm{Wu}-$ Fen Mountain (RCWF). As tracked Typhoon Aere made landfall from 0900 UTC 24 to 0600 UTC 25 August 2004, as shown in Fig. 1. Typhoon Aere attained its maximum intensity (with a minimum sea-level pressure of $954 \mathrm{hPa}$ ) as it moved close to Taiwan, producing very heavy rainfall on the windward slopes of the Snow Mountain Range (SMR). The 15-h accumulated rainfalls for Taiwan Island (from 1200 UTC 24 to 0300 UTC 25 August 2004) were indicated by the bold solid lines in Fig. 1. Over $200 \mathrm{~mm}$ of precipitation fell on the windward slopes in the northern and central parts of Taiwan. Regions with rainfall exceeding $500 \mathrm{~mm}$ were mostly located over the SMR. The maximum accumulated rainfall reached up to $759.5 \mathrm{~mm}$ in 15 hours. The shortest distance between the northern tip of Taiwan and the center of Typhoon Aere was less than $20 \mathrm{~km}$, and the RCWF radar Doppler wind range is $230 \mathrm{~km}$, so the RCWF radar was able to observe the major circulation structure of the typhoon's core area at those positions. Afterward, Typhoon Aere quickly moved toward mainland China, and dissipated rapidly after it made landfall.

The RCWF radar is a "Weather Surveillance Radar-1988 Doppler (WSR88D)" radar with $10 \mathrm{~cm}$ wave length. It is located on Wu-Fen Mountain (766 m) with an observational range of $460 \mathrm{~km}$ for reflectivity and $230 \mathrm{~km}$ for Doppler radial velocity. The observational coverage of Doppler radial velocity at the lowest elevation angle is illustrated in Fig. 1 by the solid circle, and the coverage at
$3 \mathrm{~km}$ is indicated by the dashed circle. From 0900 UTC to 1500 UTC 24 August, the low level coverage covers only half of the core circulation. From 1500 UTC 24 August to 0300 UTC 25 August, most of the core circulation of typhoon Aere can be observed by radar. Figure 2 shows the radar reflectivity at the lowest elevation angle $\left(0.5^{\circ}\right)$ and the Doppler velocities that were processed after data thinning at the $3 \mathrm{~km}$ level. Following convention, positive (negative) values of Doppler velocity indicate movement away from (toward) the radar. The complete precipitation patterns of the typhoon were revealed in the radar reflectivity (Fig. 2a), but the Doppler velocities obtained from the RCWF radar at 1200 UTC 24 August can only be derived for the western portion of the typhoon (Fig. 2b). As Typhoon Aere moved closer to the northern part of Taiwan, more features of the typhoon circulation were observed by the RCWF radar. When typhoon Aere passed through the northern part of Taiwan, the whole eye wall region could be observed by the radar, the reflectivity and Doppler velocity at 0000 UTC 25 August are shown in Figs. 2c and d. It should be noted that when the typhoon moved closer to Taiwan, its circulation was greatly influenced by the topography. The radar reflectivity (Figs. 2a, c) revealed that the pattern of reflectivity on the windward side was parallel with the SMR. The interac-

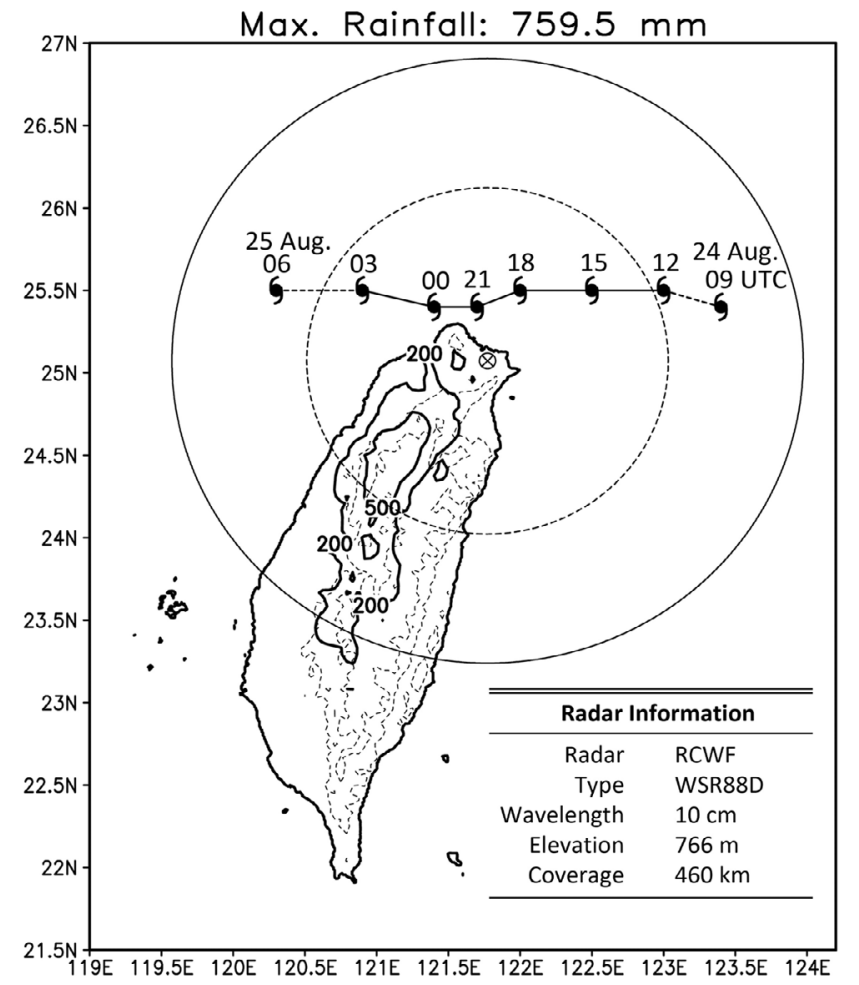

Fig. 1. Observed Typhoon Aere locations every $3 \mathrm{~h}$. The observed precipitation accumulated from 1200 UTC 24 to 0300 UTC 25 . The topography of Taiwan is shown by bold lines. The ranges of radar data coverage are indicated by solid circles (radial velocity at 0.5 elevation angle) and dashed circles (radial velocity interpolated to $3 \mathrm{~km}$ ). 

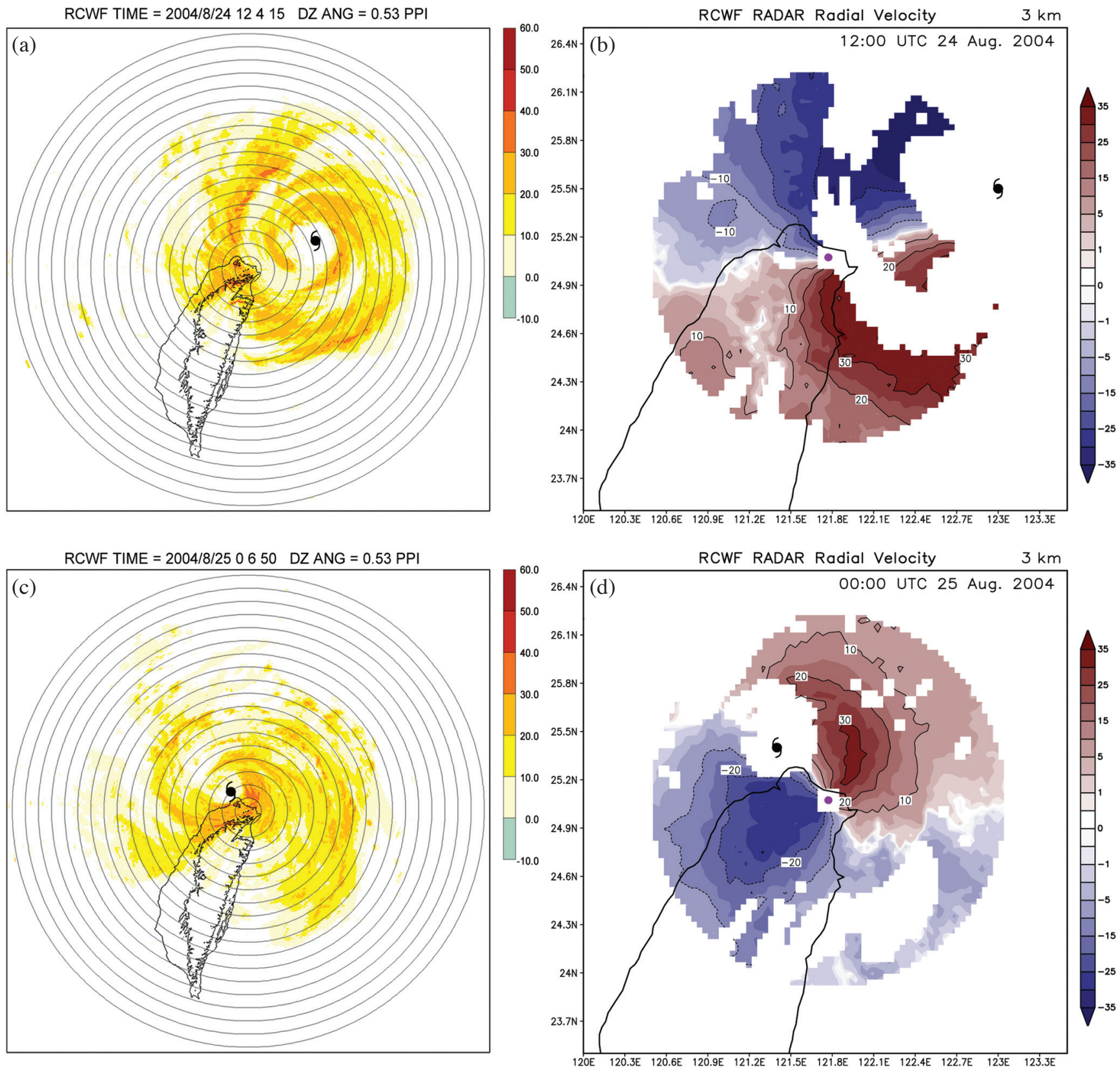

Fig. 2. RCWF radar observations showing: (a) radar reflectivity for the 0.5 elevation angle at 1200 UTC 24; (b) Doppler radial velocity for the 3 km height at 1200 UTC 24 August 2004; (c) radar reflectivity for the 0.5 elevation angle at 0000 UTC 25; and (d) Doppler radial velocity for the 3 km height at 0000 UTC 25 August.

tions between the eye wall and topography were evident in the RCWF radar observations.

One radar volume data set nearest assimilating time was used for each assimilating cycles. The data number profiles of radar observations after data thinning are shown in Fig. 3. These data were located mainly between 3 and $8 \mathrm{~km}$ in altitude and data numbers were approximately 3000 - 3500 for each time. Since the RCWF radar station is located at an elevation of $766 \mathrm{~m}$, there was little available data below $1 \mathrm{~km}$. Due to the radar beam refraction and the curvature of the earth's surface, there is a data void under the beam propagation path. The data void height is increased with distance, thus the radar coverage at a low level is smaller than at a high level.

\subsection{Experimental Design}

The MM5 model was adopted for this simulation study. Three nesting domains were employed (Fig. 4) for two-way interaction simulation. The resolutions for domains 1,2 and 


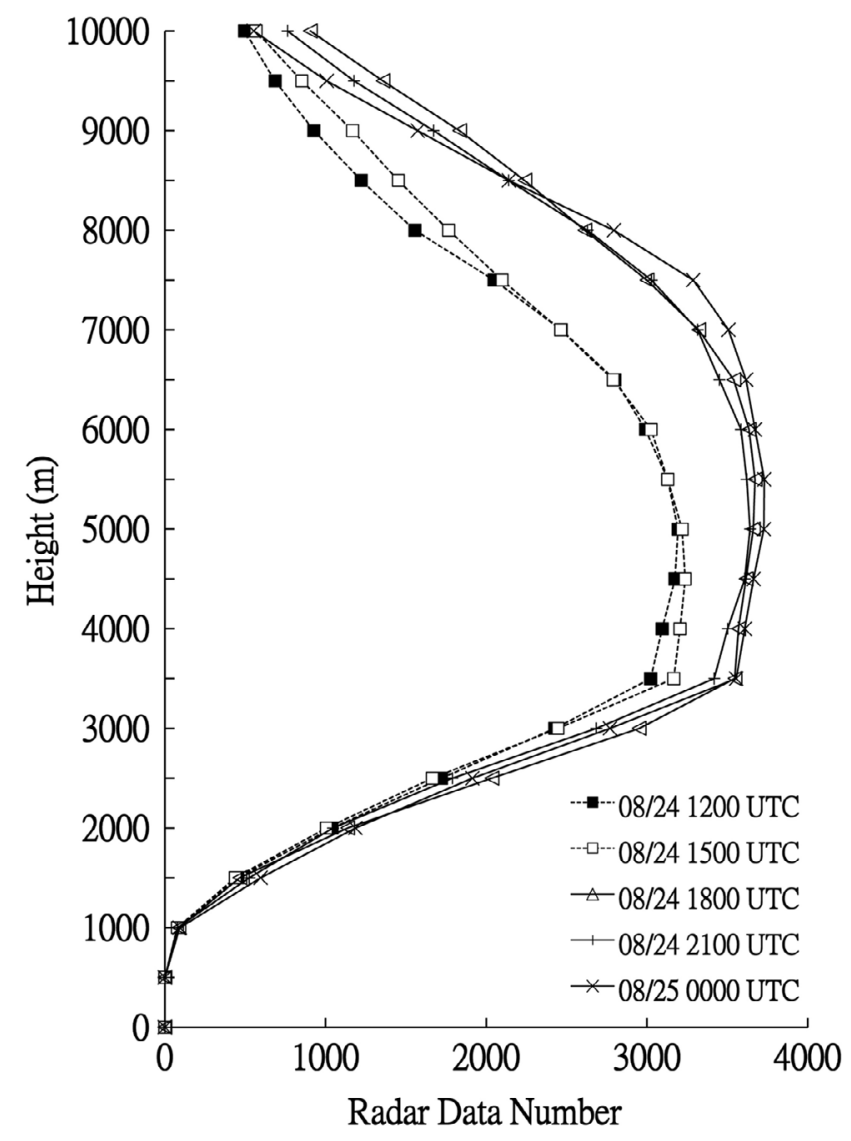

Fig. 3. Number of radar data points at different heights for each assimilation of Doppler radar wind data in one volume scan.

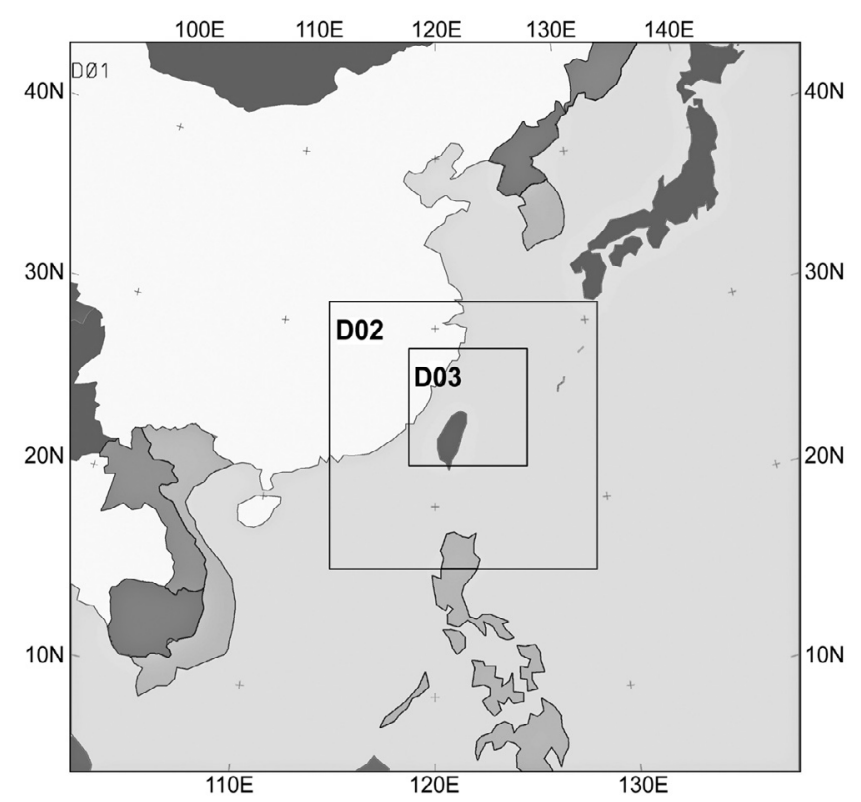

Fig. 4. Three nested domains used in the MM5 model simulations. Domain 1 has $91 \times 112$ grid points with a grid spacing of $45 \mathrm{~km}$; Domain 2 has $121 \times 121$ grid points with a grid spacing of $15 \mathrm{~km}$; and Domain 3 has $151 \times 181$ grid points with a grid spacing of $5 \mathrm{~km}$.
3 were 45,15 and $5 \mathrm{~km}$, respectively. The horizontal grid points for domains 1,2 and 3 were $91 \times 112,121 \times 121$ and $151 \times 181$, respectively. The model vertical layers extended from the surface up to $50 \mathrm{hPa}$ with 34 levels. The mixedphase microphysics (Reisner et al. 1998), Medium-Range Forecast (MRF) boundary layer parameterization (Hong and Pan 1996), cloud radiation scheme for all domains and Grell cumulus parameterization for the outer 2 domains were activated (Grell 1993). For the initial conditions we used the $1^{\circ} \times 1^{\circ}$ analysis data from the National Center for Environmental Prediction (NCEP) Global Forecast System (GFS), and the boundary conditions were updated every 3 hours. The MM5 3D-VAR system was used to assimilate observation data including conventional GTS and Doppler velocity data.

The experiments were aimed at evaluating the benefit of 3D-VAR analyses from the Doppler velocity data and the influence of data assimilation on MM5 model predictions. A schematic diagram of the control and cycling assimilating experiments is shown in Fig. 5. The cycling assimilations and warm-start simulations (initial condition retains the liquid water content from the simulation) were launched 24 hours after the initial MM5 model forecast time, 1200 UTC 23 August. The assimilation experiments were conducted from 1200 UTC 24 August until 0000 UTC 25 August. During this period, Typhoon Aere was closer to Taiwan and the RCWF radar observed the major portion of the typhoon core structures. Those radar observations can be assimilated into model simulation. The details of the cycling experiments are described below:

CTL: No observations were assimilated in the control experiment. The MM5 predictive time was 39 hours.

GTS: The impact of conventional data on typhoon prediction was examined in this experiment. GTS data were assimilated every 12 hours from 1200 UTC 24 to 0000 UTC 25 August.

DRV: Only Doppler velocity data was assimilated in this experiment. The procedure was updated by cycling data assimilation every 3 hours for a total of 5 cycles.

GAD:3D-VAR data was updated every 3 hours for a total of 5 cycles afterwards. Conventional data and RCWF Doppler wind were both assimilated. The Doppler velocities were incorporated into the 3D-VAR analyses at 3-h intervals, and conventional data were incorporated at 12 -h intervals.

RV3: This is a 3-cycle assimilating experiment and only Doppler velocity data was used. The launch time was 30 hours after the initial time. Compared to the DRV experiment, RV3 removed the earlier assimilating steps which contained the incomplete radar coverage of typhoon circulation.

In the impact experiments, the update cycling assimilating processes included complicated interactions between 


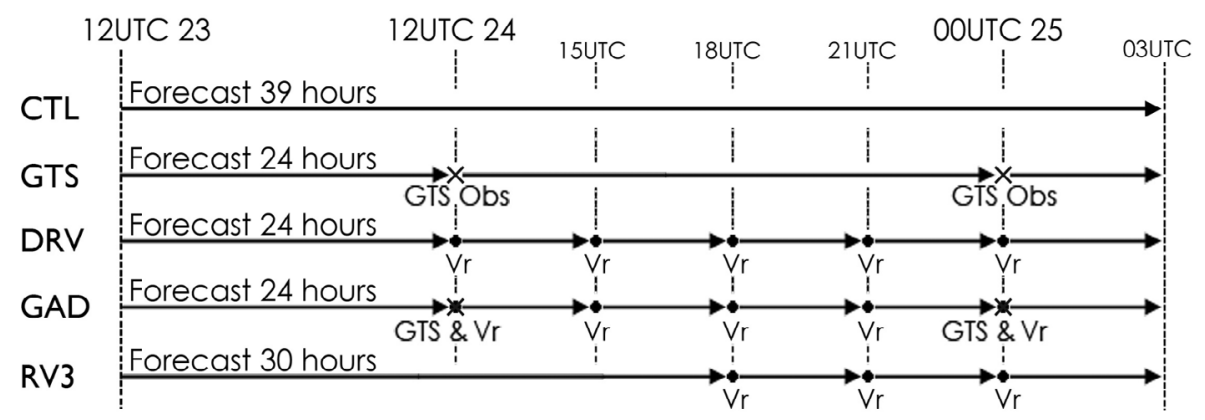

Fig. 5. Schematic diagram showing the simulated period for the CTL experiment and the frequency and types of observations assimilated for the GTS, DRV, GAD and RV3 experiments.

assimilation and simulation many times. It is difficult to distinguish the individual influences of assimilation and simulation. To compare the effectiveness of conventional data assimilation and Doppler radial velocity assimilation on typhoon simulation, we designed several sensitivity experiments in which different types of observational data were assimilated with the same background field. Due to the better availability of sounding data at 0000 UTC, the sensitivity experiments were started at 0000 UTC 25 August for 6 hours prediction. Three kinds of meteorological observations in Taiwan including conventional surface station data, sounding data and the Doppler radial wind data were used for the assimilating sensitivity experiments. The observations and typical number of data points used in domain 3 for each experiment are listed in Table 1. The SEN-NON experiment was an experiment without any data assimilation. In the SEN-SFC, SEN-SND and SEN-DRV experiments, surface station data, sounding data and Doppler radial wind data were assimilated, respectively.

\section{RESULTS OF CYCLING ASSIMILATING EX- PERIMENTS}

\subsection{Tracks}

The impact of RCWF Doppler velocities on Aere's prediction was assessed by comparing results from the data assimilation experiments with the CTL results. Figure 6 shows the locations of the observed typhoon center (cross), as well as the locations predicted by CTL (closed circle), GTS (open circle), DRV (open square) and GAD (closed square) from 1200 UTC 24 to 0300 UTC 25, and RV3 (closed triangle) from 1800 UTC 24 to 0300 UTC $25 \mathrm{Au}-$ gust (3-h time intervals).

The observed typhoon track moved almost straight west, being deflected slightly southward as it approached Taiwan. In all simulation experiments, the moving speed of the predicted typhoon center was too slow in the first 24 hour simulation time frame; therefore, at the starting time (1200 UTC 24 August) of assimilation, the position of the typhoon center was about $100 \mathrm{~km}$ east of the observed typhoon position.

In the CTL simulation, the typhoon moved westward during the first 9 hours (relative to the initial assimilation time, 1200 UTC 24 August), then turned southwest toward Taiwan and made landfall in the last 6 hours. The GTS experiment predicted a similar path to that of CTL, but the typhoon turned westward at 0000 UTC 25 August and made an earlier landfall. In the DRV, the movement of the typhoon center was deflected toward the south during the second assimilation cycle. Because the typhoon center was still far away from Taiwan during the first 2 cycles, the RCWF radar only observed the western part of typhoon Aere. Moreover, since radar can only obtain signals from precipitating particles in the air, the radar wind information would be lost in clear air regions, especially in the eye area. The deflection of the typhoon movement in the DRV experiment may have been caused by incomplete radar coverage and uneven radar data distribution. The same situation of moving deflection also occurred in the GAD experiment. However, when Typhoon Aere moved closer to Taiwan, its entire core region could be observed by radar. Then the simulated typhoon positions from DRV and GAD were closer to the observed track. In the mean time the CTL simulated typhoon made landfall. In the RV3 experiment, the radar data was assimilated later than DRV, and could cover most

Table 1. The observations and typical number of data points used in model domain 3 for sensitivity experiments at 0000 UTC 25 August 2004.

\begin{tabular}{ll}
\hline Case & $\begin{array}{l}\text { Assimilated data } \\
\text { (typical number of data points in domain 3) }\end{array}$ \\
\hline SEN-NON & None \\
SEN-SFC & Surface station data (37) \\
SEN-SND & Upper air soundings (6) \\
SEN-DRV & Doppler radial velocity (as shown in Fig. 3) \\
\hline
\end{tabular}


The Track of Typhoon AERE

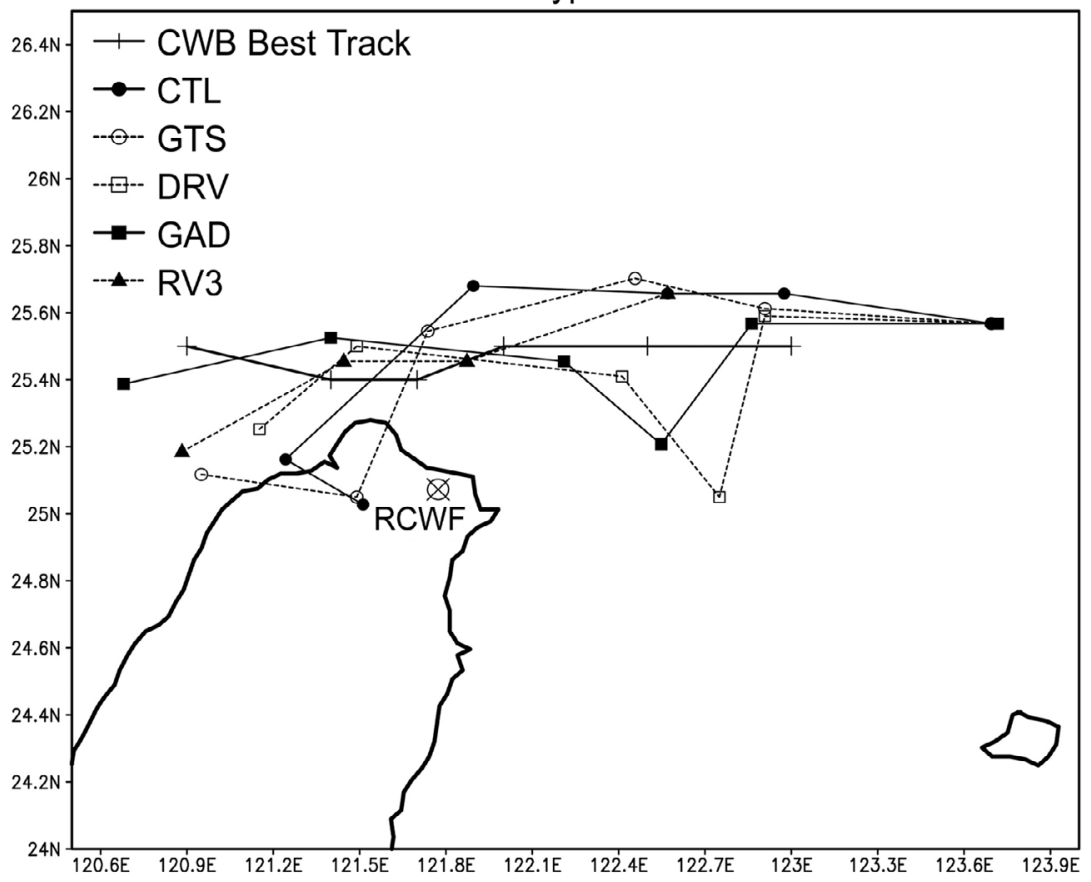

Fig. 6. The CWB best track of Typhoon Aere and the simulated typhoon tracks. The typhoon positions of: (1) best track (crossed symbols); (2) CTL (closed circles); (3) GTS (open circles with dashed lines); (4) DRV (open squares with dashed lines); (5) GAD (closed squares); and (6) RV3 (closed triangles) are plotted every $3 \mathrm{~h}$ from 1200 UTC 24 to 0300 UTC 25 August 2004.

of the core region of the typhoon circulation. Although RV3 was started later than DRV, the result showed that a similar track deflection was avoided and the simulated track was similar to DRV at the last 3 assimilation cycles. A comparison of the DRV and GAD reveals that the typhoon center in GAD moved farther west and much closer to the observation position in the final update cycle because of additional GTS data assimilation. The GTS data assimilation provided a more accurate environmental flow and maintained the typhoon moving speed. Although GTS data were assimilated only twice at 12 -h intervals in GAD, the 3 -h predictions for each cycle showed faster movement than the DRV. The center of the typhoon moved westward from land to ocean after the second data assimilation in the GTS experiment. Overall, there was a tendency for the typhoon movement to be deflected southwest in all the simulations. Through the Doppler radial velocity data assimilations in GAD, DRV and RV3, the track deflection was improved, the simulated typhoon movement was forced westward and the simulated center positions were much closer to the observations.

\subsection{Intensity}

The predicted minimum sea level pressures (SLP) of the typhoon center are shown in Fig. 7. At the launch time of assimilation (1200 UTC 24 August), the typhoon central pressure was over-predicted by about $25 \mathrm{hPa}$, leading to the reduced simulated typhoon intensity of the following experiments. The major typhoon prediction problems are caused by many factors including insufficient observations over the oceans, inappropriate treatments of model physics, such as unsuitable physical parameterization resulting inadequate cloud-dynamics interactions, insufficient model resolution and the complicated influence of the CMR. Because the vortex bogussing scheme was not applied to construct the initial circulation in all the experiments, the typhoon central pressure was not adequately strengthened. The simulated minimum SLP in the GTS experiment (assimilation of GTS data only) showed a similar tendency to the CTL results, but with slightly higher values than those of CTL. On the contrary, the DRV, GAD and RV3 produced relatively better minimum SLP, implying a positive influence of the radar data assimilation on typhoon intensity. The results also illustrated that the minimum SLP of DRV and GAD decreased after 1500 UTC 24 August. Although the launch time of the RV3 was delayed 6 hours compared to DRV and GAD, the simulated minimum SLP in RV3 decreased to be closer to DRV and GAD after one hour simulations. By contrast, the GAD typhoon intensity was slightly stronger than that of DRV, especially for the last cycle. The observed minimum SLP in the whole lifetime of Aere was $954 \mathrm{hPa}$, but the GAD predicted the minimum SLP was just $978 \mathrm{hPa}$, an overestimation of $24 \mathrm{hPa}$. In comparison with the CTL, the error of the simulated central SLP was reduced by about $25 \%$. 


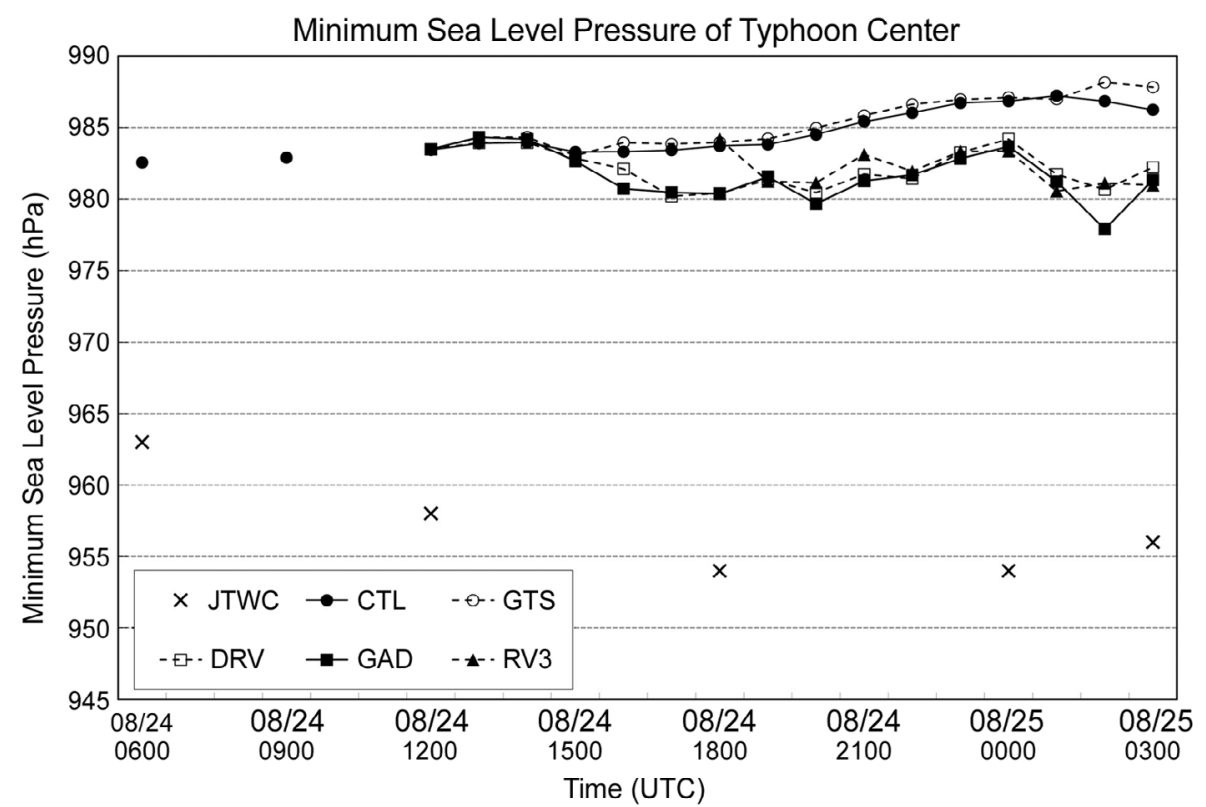

Fig. 7. Time series of the intensity (hPa) of Aere from JTWC analysis (crossed symbols) and the predicted minimum sea level pressure of the typhoon center for (1) CTL (closed circles); (2) GTS (open circles with dashed lines); (3) DRV (open squares with dashed lines); (4) GAD (closed squares); and (5) RV3 (closed triangles). The symbols for minimum sea level pressure within the assimilated period for each experiment are connected with a line.

\subsection{Structure}

The wind fields retrieved by the dual-radar analysis at 0030 UTC 25 August are shown in Fig. 8. The different levels of shading indicate the isotach beginning from $15 \mathrm{~m} \mathrm{~s}^{-1}$ with increment $5 \mathrm{~m} \mathrm{~s}^{-1}$. The figure shows that the typhoon center was located in the northern Taiwan Strait with cyclonic circulation over northern Taiwan. At the $3 \mathrm{~km}$ level, south-westerly winds with speeds exceeding $20 \mathrm{~m} \mathrm{~s}^{-1}$ prevailed in the northern part of SMR (middle of the box in Fig. 8). Figure 9 shows the sea level pressure, horizontal wind and horizontal divergence fields at the same time. Compared to the dual-radar retrieved wind (Fig. 8), the DRV, GAD and RV3 experiments correctly simulated the horizontal wind, especially GAD, which produced the best results over the SMR. Notably, the wind speed over Taiwan was seriously underestimated in CTL and GTS where the directions were erroneously north-westerly. The SLP and wind fields in CTL (Fig. 9a) show that the typhoon already made landfall and the typhoon core structure was destroyed by the topography. As a result, its intensity weakened and its structure was disrupted. In the GTS experiment (Fig. 9b), the predicted typhoon center moved into the Taiwan straits after GTS data assimilation. However, the pressure pattern shows an asymmetric circulation and a weak wind field over northern Taiwan. In the DRV (Fig. 9c), the typhoon intensity increased after the fifth data assimilation and its circulation structure was more symmetrical and circular. Figure 9d is the GAD predicted SLP showing the strongest intensity, and the position is farthest away from Taiwan of all the experiments. The SLP pattern around the typhoon center was asymmetric in GTS and was slightly asymmetric in GAD. Due to the uneven spatial distribution of the GTS data, the typhoon circulation features could not be resolved well and the symmetric pattern was changed by GTS data assimilation. In this case, the typhoon circulation

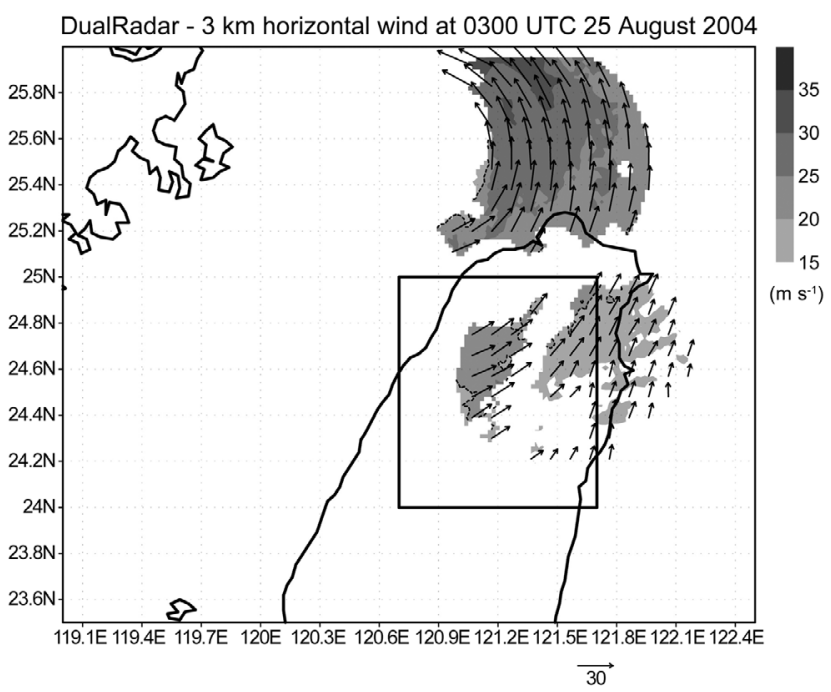

Fig. 8. The horizontal wind from Dual-Radar analysis derived by RCWF and the National Central University radar (NCU) over $3 \mathrm{~km}$ at 0300 UTC 25 August 2004. The different levels of shading indicate the isotach beginning from $15 \mathrm{~m} \mathrm{~s}^{-1}$ with increment $5 \mathrm{~m} \mathrm{~s}^{-1}$. The wind vector scale for $30 \mathrm{~m} \mathrm{~s}^{-1}$ is labelled in the lower right corner. The box signifies the SMR. 

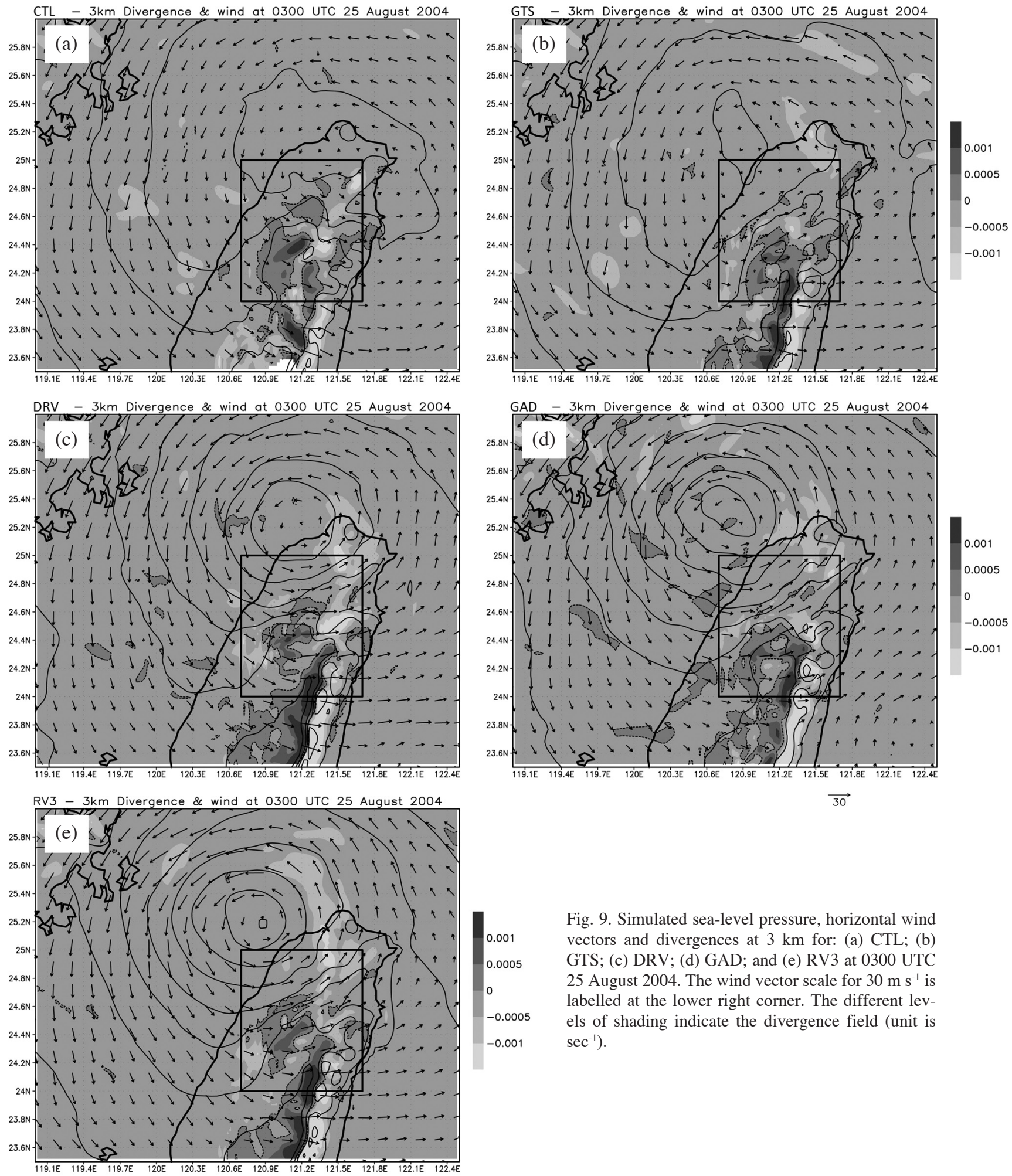

Fig. 9. Simulated sea-level pressure, horizontal wind vectors and divergences at $3 \mathrm{~km}$ for: (a) CTL; (b) GTS; (c) DRV; (d) GAD; and (e) RV3 at 0300 UTC 25 August 2004. The wind vector scale for $30 \mathrm{~m} \mathrm{~s}^{-1}$ is labelled at the lower right corner. The different levels of shading indicate the divergence field (unit is $\left.\sec ^{-1}\right)$.

is observed in more detail by the Doppler radar, and the data assimilation with radar wind helps the model produce more realistic circulation structures. The horizontal divergence fields from all experiments showed a divergent flow at $3 \mathrm{~km}$ over SMR indicating the flow moved around the mountain ridges rather than rising above them. At the same time, comparing the wind speeds in Figs. 8 and 10, the CTL and GTS underestimated the wind speed fields (about $15 \mathrm{~m} \mathrm{~s}^{-1}$ ) over 

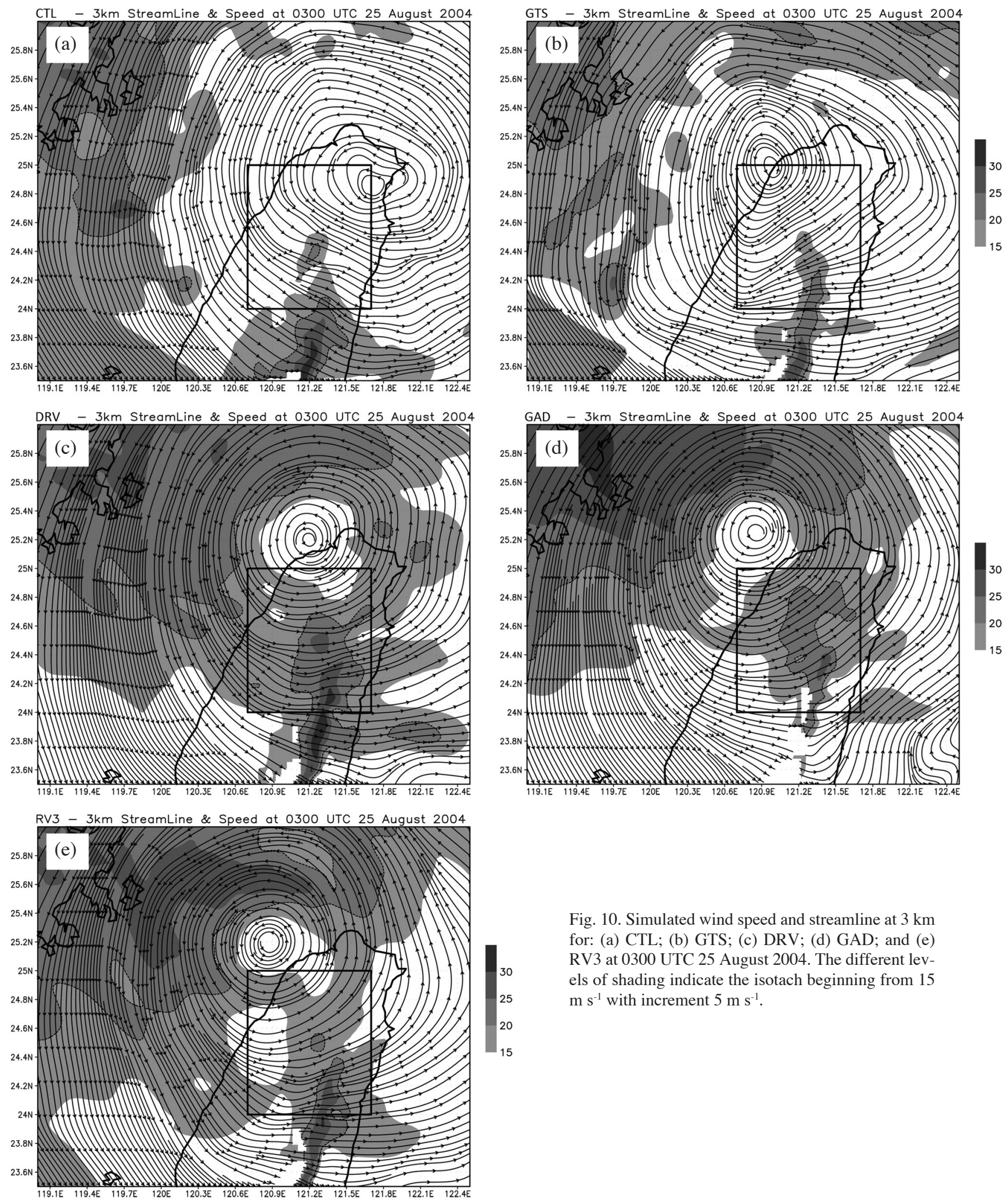

Fig. 10. Simulated wind speed and streamline at $3 \mathrm{~km}$ for: (a) CTL; (b) GTS; (c) DRV; (d) GAD; and (e) RV3 at 0300 UTC 25 August 2004. The different levels of shading indicate the isotach beginning from 15 $\mathrm{m} \mathrm{s}^{-1}$ with increment $5 \mathrm{~m} \mathrm{~s}^{-1}$.

north Taiwan. In contrast, DRV, GAD and RV3 produced stronger wind speeds near the typhoon central area. The single Doppler radar's radial wind data assimilation is able to retrieve the similar wind speed to the dual-Doppler syn- thesis wind exceeding $20 \mathrm{~m} \mathrm{~s}^{-1}$ over the SMR.

The observed and simulated reflectivity fields are shown in Fig. 11. The observations (Fig. 11a) showed the strong reflectivity was mainly in the southern part of the 

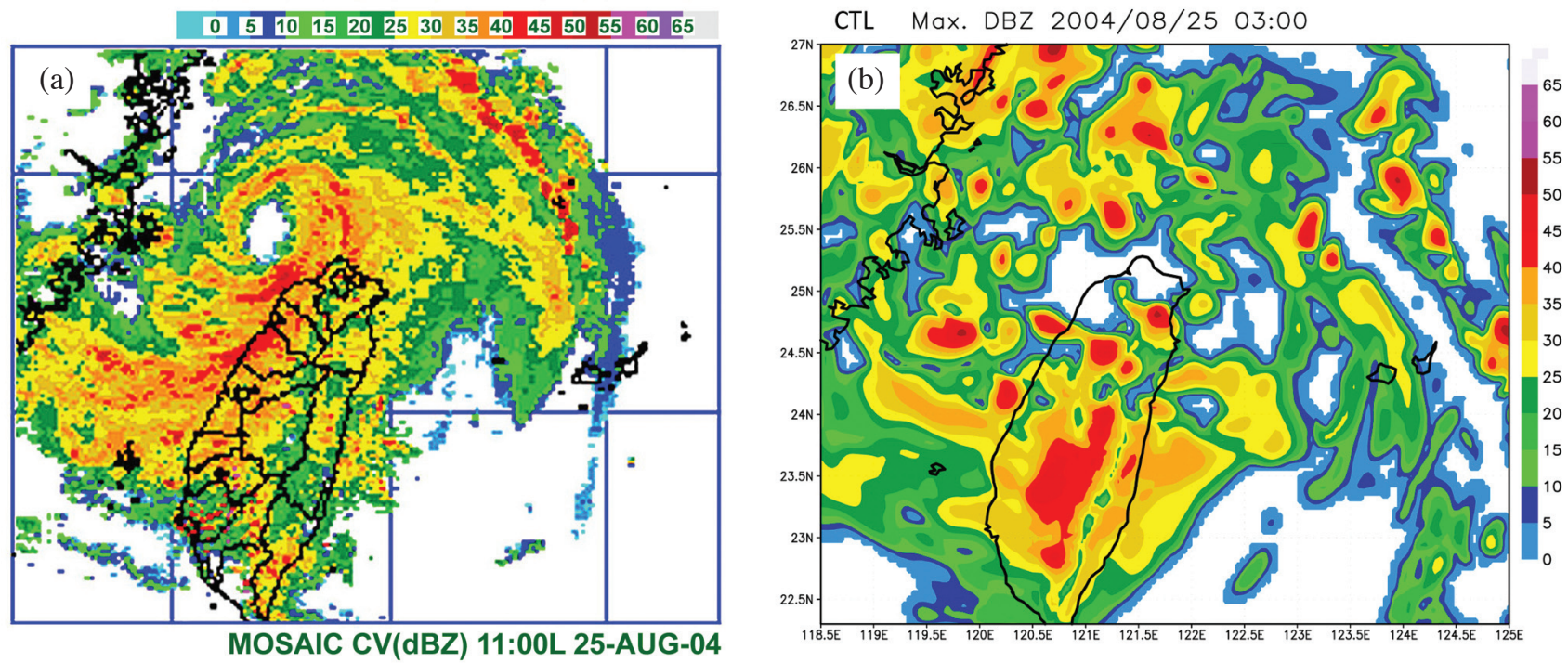

GTS Max. DBZ 2004/08/25 03:00
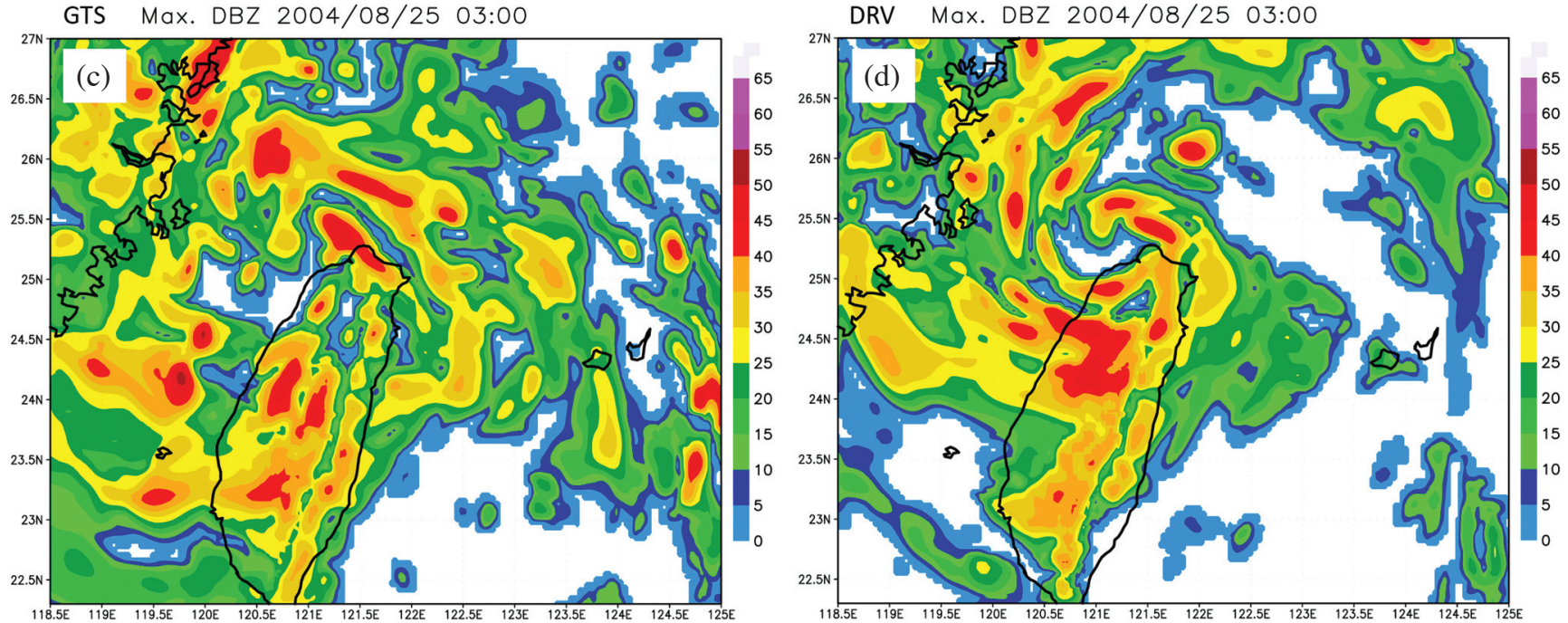

GAD Max. DBZ 2004/08/25 03:00

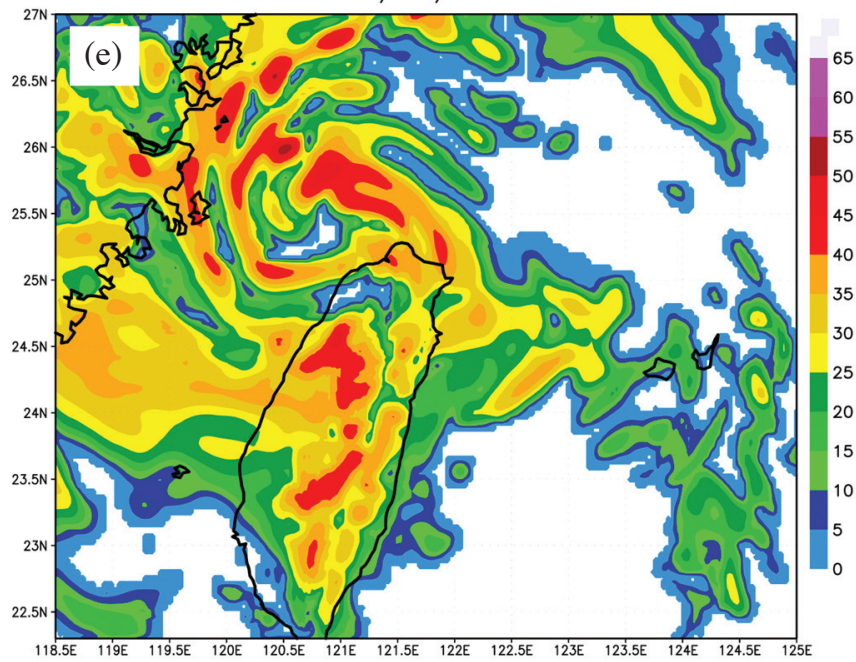

RV3 Max. DBZ 2004/08/25 03:00

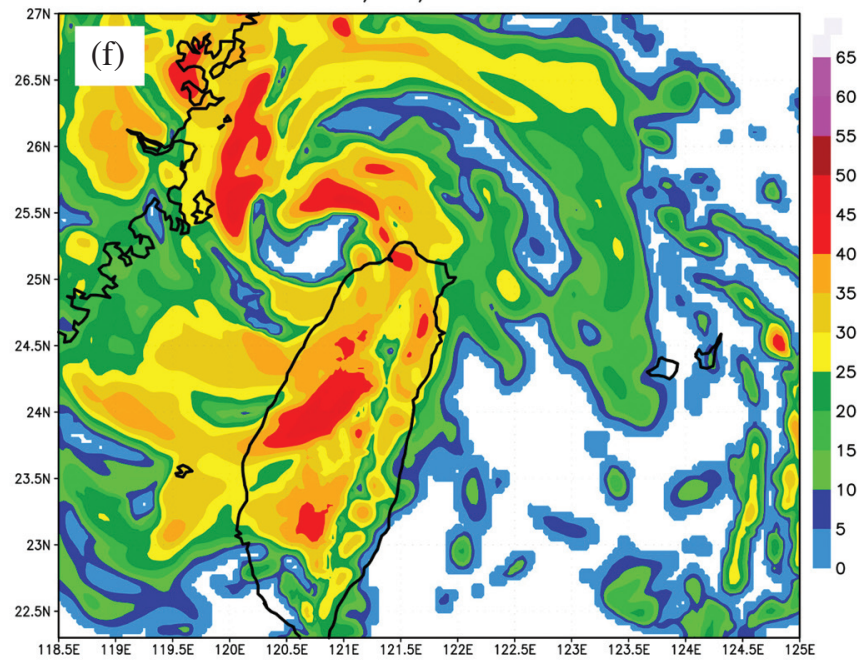

Fig. 11. (a) RCWF radar observed and model simulated Radar reflectivity (dBZ) for experiments (b) CTL; (c) GTS; (d) DRV; (e) GAD; and (e) RV3 at 0300 UTC 25 August. 
typhoon and the outer rain band extended from the mountain area of central Taiwan to the southeast coast of mainland China. The simulated reflectivities in CTL (Fig. 11b) and GTS (Fig. 11c) were not well organized and the eye wall structures were not obvious. In the DRV and GAD, the reflectivity patterns showed a more organized eye wall structure. In accordance with the observations, the simulated outer rain bands extended across the central Taiwan Strait. The RV3 (Fig. 11f) also simulated a similar rain band but its location was more southward. Figure 12 shows the
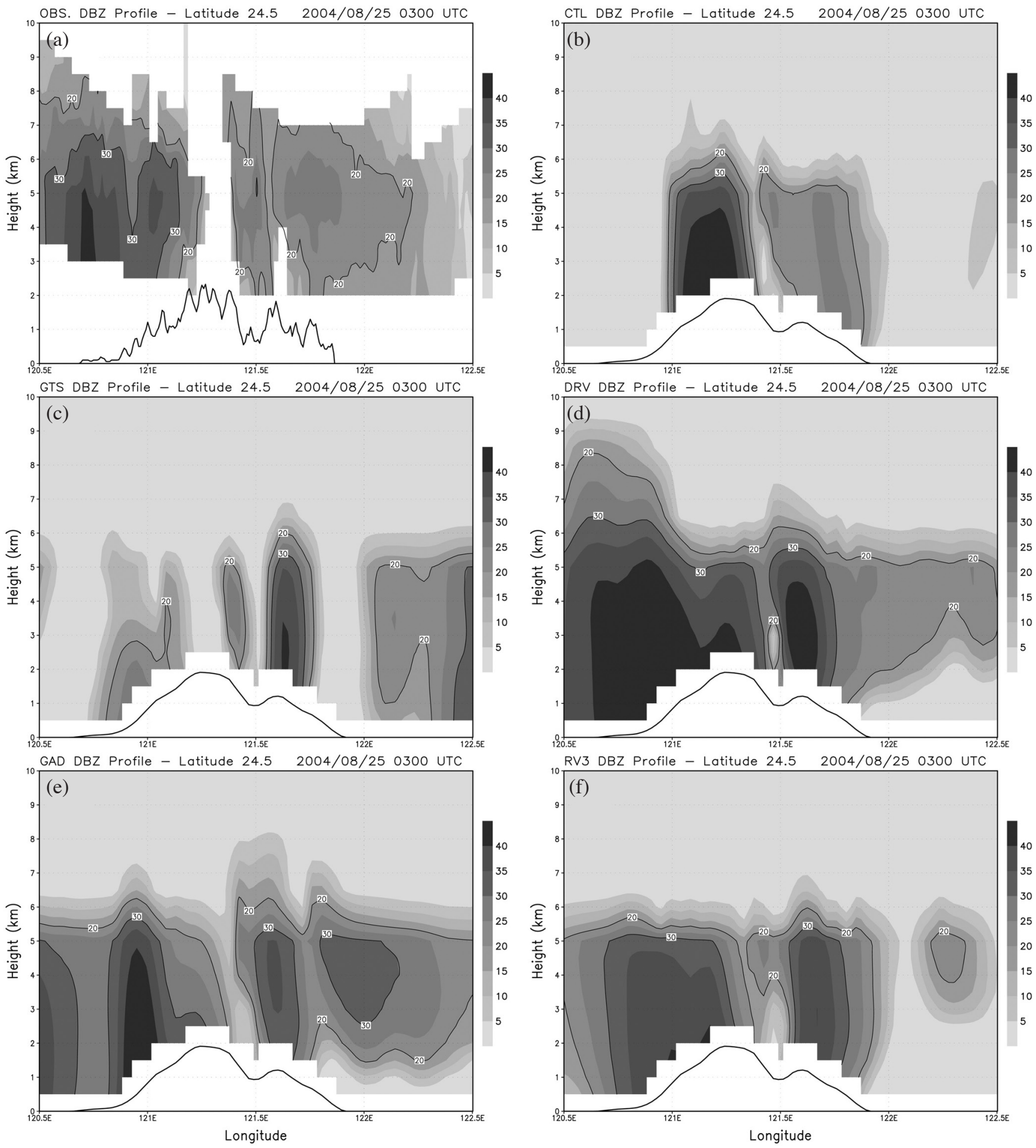

Fig. 12. Corresponding east-west vertical cross section through the latitude of $24.5^{\circ}$ showing (a) RCWF radar observed and model simulated Radar reflectivity (dBZ) for experiments (b) CTL; (c) GTS; (d) DRV; (e) GAD; and (f) RV3 at 0300 UTC 25 August. 
vertical cross section through the $24.5^{\circ}$ of latitude over the SMR. The observed high reflectivity (Fig. 12a) resided on the windward side of the mountain slope and the weaker stratiform pattern hung over on the leeward side. In CTL (Fig. 12b), the simulated reflectivity occurred mostly on the mountain top, indicating the lack of precipitation over the western plain. The GTS experiment (Fig. 12c) seriously underestimated the reflectivity on the windward side and misrepresented reflectivity on the leeward side (with a stronger convective rather than stratiform pattern). In the DRV, GAD and RV3 (Figs. 12d - f), the simulated reflectivity distributions were generally closer to the observed pattern. For example, the $20 \mathrm{dBZ}$ contour of simulated reflectivity in DRV can reach $8 \mathrm{~km}$, similar to the observation on the windward side. From Figs. 12a and f, we also note that the stratiform precipitation structure on the leeward side was not well simulated in RV3.

\subsection{Rainfall}

The observed and simulated 3-h accumulated rainfall fields at 0300 UTC 25 August are shown in Fig. 13. The square box in Fig. 13 represents the area where the heaviest rainfall (Fig. 13a) was observed over the SMR. It is clear that the simulated 3-h accumulated rainfall was weaker than that of the observation in all experiments due to the weaker simulated typhoon intensity. In the CTL (Fig. 13b) and GTS (Fig. 13c) experiments, the simulated typhoon landed in
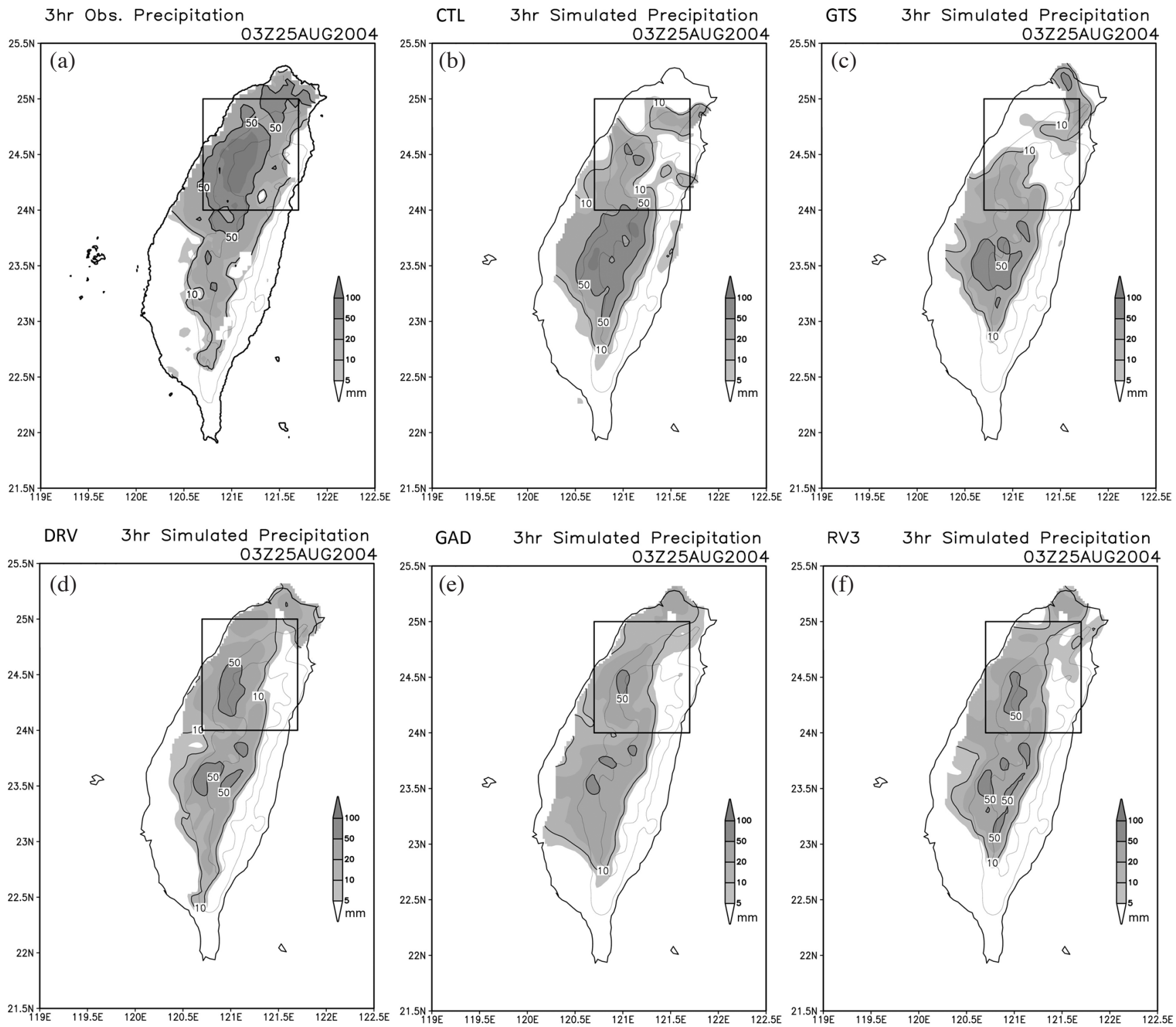

Fig. 13. Rainfall distributions (mm) showing: (a) 3-h observed precipitation and 3-h predicted precipitation by (b) CTL; (c) GTS; (d) DRV; (e) GAD; and (f) RV3 at 0300 UTC 25 August 2004. 
Taiwan, hence the heavy rainfall distributed farther to the south. The DRV, GAD and RV3 (Figs. 13d - f) captured the rainfall distribution pattern around the SMR much better than the CTL and GTS experiments.

Owing to the variations of the simulated typhoon center locations in Fig. 9, the wind directions associated with the typhoon on the windward side of the SMR are different. The winds were north-westerly in CTL and GTS (Figs. 9a, b) and more westerly in DRV, GAD and RV3 (Figs. 9d - f) respectively. As the airflow encounters the mountainous topography, it might climb over or be deflected to go around the mountains. The vertical wind component associated with airflow over mountains is closely related to the slope of terrain. The Froude number ( $\mathrm{Fr}$ ) can be interpreted as the ratio of the speed of flow to the speed of gravity waves. It is defined as

$F_{r}=\frac{U}{N H}, N=\sqrt{\frac{g}{\theta} \frac{\partial \theta}{\partial z}}$

where $H$ is the terrain height, $U$ is the horizontal wind speed and $N$ is the buoyancy frequency. $g$ is gravitational acceleration, and $\theta$ is potential temperature. For small Fr, some of the low-altitude upstream air is blocked by the mountains and the air flows around the hill. For larger Fr, the airflow climbs more easily over the mountains. To obtain a representative Fr, the upstream wind speed is calculated from an area average within $0.5^{\circ} \times 0.5^{\circ}$ and the vertical range is contained from the surface to $500 \mathrm{hPa}$ over the mid-Taiwan Strait. The Fr counted at 0300 UTC 25, were $0.53,0.43$, 0.77, 0.69 and 0.82 for CTL, GTS, DRV, GAD and RV3, respectively. The DRV, GAD and RV3 had higher Fr numbers due to the larger upstream wind speed, which provided a favorable situation for the flow to climb the mountains. The lifting effect of the SMR can be determined mainly by the parallel topographic gradient component of typhoon circulation. This lifting effect of the topography might be partially responsible for the distribution of the heavy rainfall pattern.

The lifting effect (LE) of the terrain can be formulated as

$L E \equiv V \cdot \nabla h=u \frac{\partial h}{\partial x}+v \frac{\partial h}{\partial y}$

where $h$ is the terrain height and $V$ is the horizontal wind vector; the units of $L E$ are $\mathrm{m} \mathrm{s}^{-1}$.

Owing to the various wind directions in the experiments, the distributions of the topographic lifting effect are different. Figure 14 shows the distributions of the lifting effect for these four experiments at 0300 UTC 25 August 2004. A comparison between the simulated precipitation area (Fig. 13) and the corresponding LE pattern shows that the areas of distinct rainfall are closely related to the areas of topographic lifting. The LE pattern of CTL (Fig. 14a) was distributed around the north SMR and was aligned from northeast to southwest along the first constant height contour line $(500 \mathrm{~m})$. Because the northwest wind was perpendicular to the north SMR at this time, the northern precipitation region was distributed mainly on the windward mountain slope. The maximum LE area of the CTL experiment appeared in the southern mountain area of Taiwan. Therefore the simulated maximum rainfall also occurred in the southern mountain area. It is clear that the LE pattern of GTS (Fig. 14b) indicated less apparent mechanical uplifting than the other experiments in northern Taiwan.

The DRV, GAD and RV3 experiments (Figs. 14c - e) show the largest LEs were on the SMR and concentrated in the southwest part of the boxed area, where the mountains align almost directly from north to south. As a result, heavy rainfall was induced by the eastward wind flow in the high LE regions. Furthermore, the simulated wind speed of DRV, GAD and RV3 increased in north-western Taiwan. The LE distributions extended to the slope area below $500 \mathrm{~m}$. Although the terrain height is not very high near these foothill regions, the stronger wind speed still has the potential to induce vertical motion. Because the wind speed of the GAD and RV3 were smaller than DRV, the LE distributions were similar to the DRV but weaker, and the accumulated rainfall over the SMR was also smaller than DRV.

Rainfall observations obtained from the Central Weather Bureau (CWB) for the entire island of Taiwan were used to verify the experiments (Figs. 13a - f). The Threat Score (TS) and BIAS are calculated for all cycling experiments and are defined as

$T S=\frac{C}{F+O-C}$

$B I A S=\frac{F}{O}$

where $O$ is the number of rainfall events occurring for each threshold, $F$ is the number of predicted rainfall events interpolated into observed points, and $C$ is the number of the precipitation events which were correctly predicted. Xiao et al. (2005) demonstrated that radar radial velocity data assimilation is useful for short-term rainfall prediction in a heavy rainfall case, especially for the first three hour forecast. Therefore, we also focused on verification of the 3-h rainfall predictions in every assimilating cycle.

Figure 15 shows the comparison of different thresholds of TS (bar) and BIAS (line) for 3-h rainfall prediction at 0300 UTC 25 August. It can be seen that the assimilation of Doppler velocity data (by DRV, GAD and RV3) led to better rainfall predictions and reduced the BIAS for thresholds 

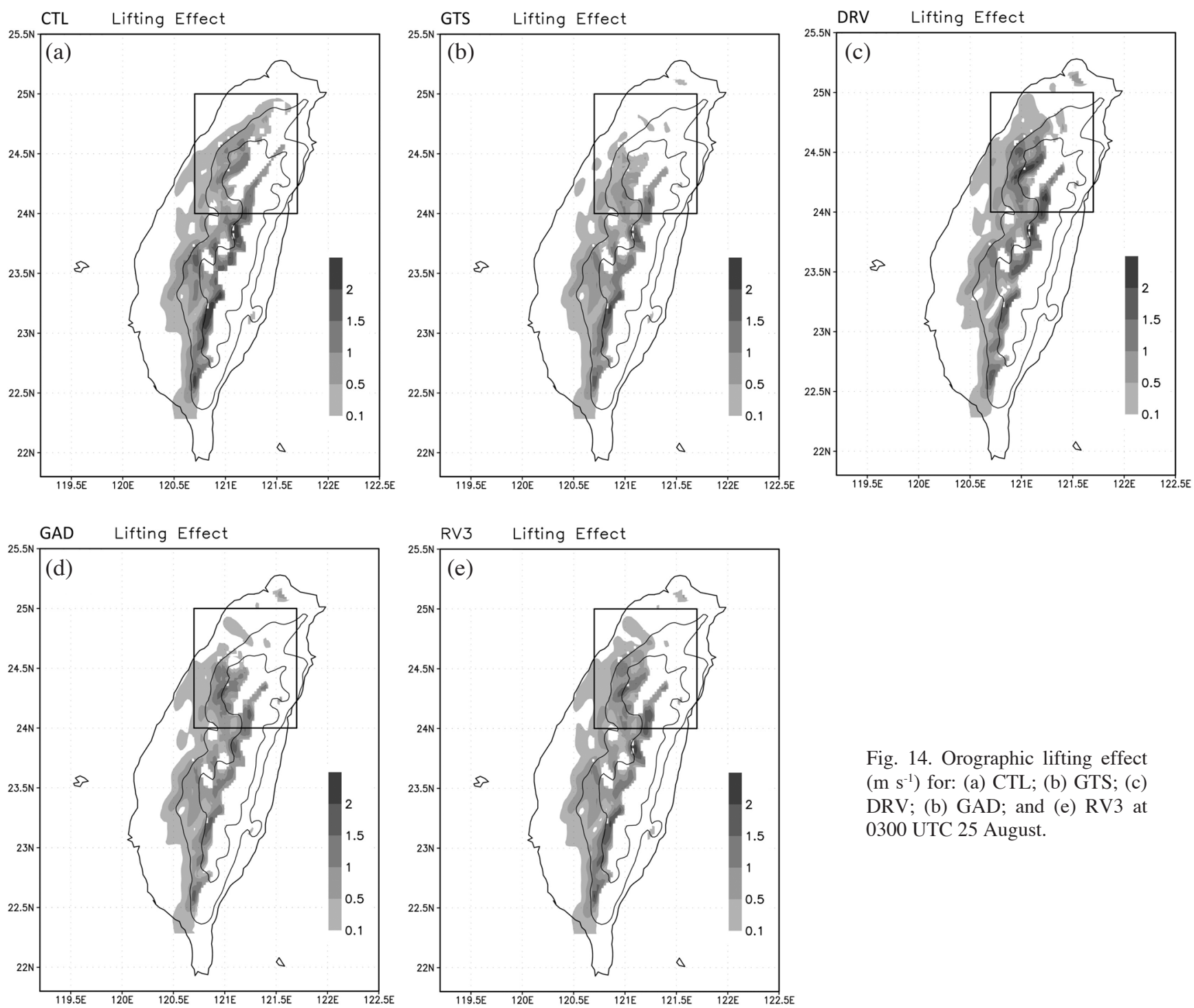

Fig. 14. Orographic lifting effect $\left(\mathrm{m} \mathrm{s}^{-1}\right.$ ) for: (a) CTL; (b) GTS; (c) DRV; (b) GAD; and (e) RV3 at 0300 UTC 25 August.

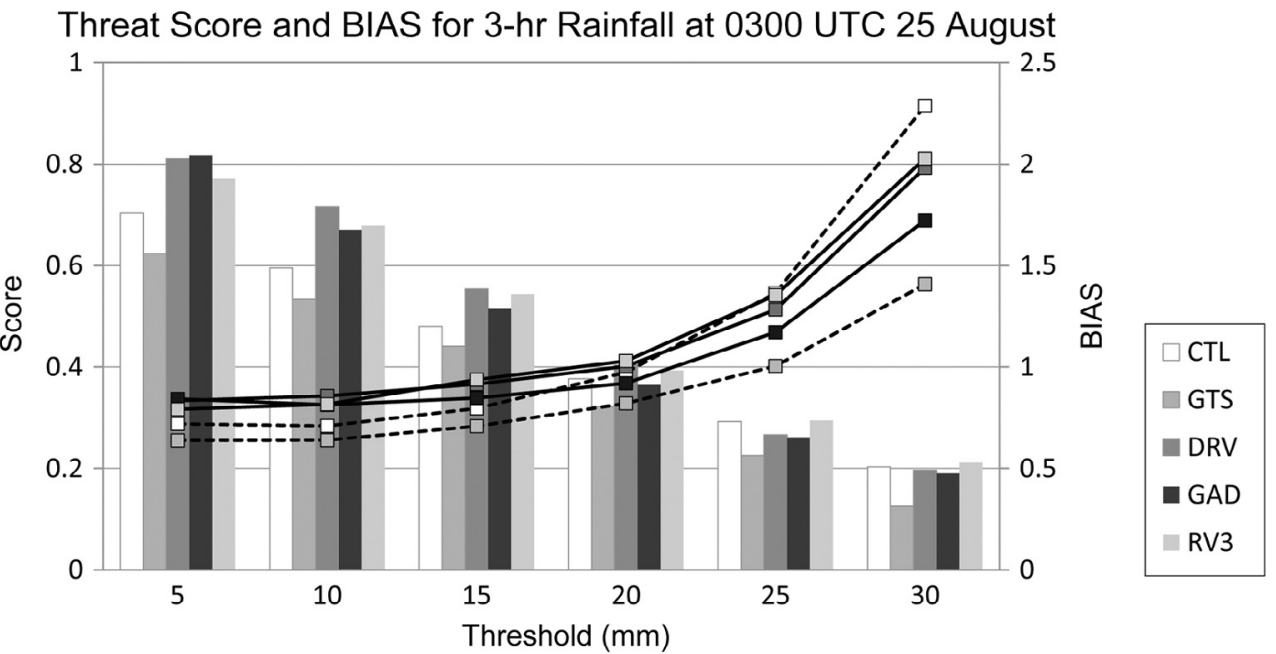

Fig. 15. Inter-comparisons of the Threat Score (bar) and BIAS (line) among CTL, GTS, DRV, GAD and RV3 with thresholds from 5 to 30 mm at 0300 UTC 15 August. 
smaller than $20 \mathrm{~mm}$. Although the assimilation of Doppler wind data contributed no obvious improvement to the TS scores for thresholds larger than $20 \mathrm{~mm}$, the BIAS scores indicated that the experiments including the Doppler wind data assimilation were able to reduce the over-prediction errors for higher accumulating rainfall. At the same time, the simulated rainfall patterns (Fig. 13) and reflectivity distributions (Figs. 11, 12) also present that the results with radar wind data assimilation are better than those without it.

In this particular case study, the SMR plays an important role in the orographic lifting effect. Due to the SMR blocking effect, the strong upward vertical motion was induced and caused heavy rainfall over the SMR when the typhoon circulation invaded northern Taiwan. From the results of the simulation experiments, we found that the limited coverage of radar observations affects the impact of radar data assimilation on typhoon predictions. When the typhoon was far away from land, the incomplete and uneven radar observation coverage of the typhoon core area caused the track deflection and even impaired the rainfall prediction afterwards. However, there were obvious improvements in the typhoon track prediction and the accompanying wind and precipitation distribution due to radar wind data assimilation when the typhoon was closer to Taiwan and the whole typhoon core area moved into the radar network's range of coverage. Although the effect of radar data assimilation has a shorter lead time, it still has forecasting value for hazard prevention and mitigation.

\section{SENSITIVITY TESTS}

In order to distinguish the effects of the 3D-VAR data assimilation of traditional surface data, sounding data and radar radial wind data, several sensitivity experiments were conducted and started at 0000 UTC 25 August. The typical numbers of assimilated data were quite different for these three kinds of sensitivity data assimilation experiments, as shown in Table 1. Although the upper air sounding data had the least data density in horizontal distribution, it still had 6 soundings within model domain 3 in experiment SEN-SND. Thirty seven surface observations were used in the inner domain in experiment SEN-SFC. The largest number of available data was Doppler radial velocity provided by radar observations. The distribution of data number with height is shown in Fig. 3. The influences of 3D-VAR data analysis at the initial time in all sensitivity experiments are shown with the wind increments in Fig. 16. The incremental wind fields were derived from the horizontal wind vectors differences between the assimilating (SEN-DRV, SEN-SND and SENSFC) and non-assimilating experiments (SEN-NON) at 0000 UTC 25 August. In SEN-DRV (Fig. 16a), there was an obvious increment of cyclonic circulation near the observed typhoon circulation. The incremental circulation center is located in the northwest of the SEN-NON vortex center.
Therefore, the ingestion of radar radial wind data caused the typhoon center in the 3D-VAR analysis to move closer toward the observation location. Assimilation of sounding data (Fig. 16b) also led to an increase in cyclonic circulation, but it was weaker than that of the SEN-DRV data. Since the center of the incremental cyclone circulation was situated to the east of the observed location, evidently, the sounding data assimilation can't correctly retrieve the circulation near the typhoon center. In experiment SEN-SFC (Fig. 16c), the incremental wind pattern did not show a relative cyclonic circulation. Instead, the surface data assimilation slightly reduced the typhoon circulation. The wind speed on the windward side of the CMR was also reduced.

From the upper air sounding over northern Taiwan, the observed wind speed (Fig. 17) increased rapidly from about $10 \mathrm{~m} \mathrm{~s}^{-1}$ at the surface to $30 \mathrm{~m} \mathrm{~s}^{-1}$ at $900 \mathrm{hPa}$. The surface station data did not provide this profile information, so the initial analysis of 3D-VAR data assimilation showed almost no adjustment to the atmospheric wind profile revealed by the non-assimilation experiment. Therefore, when the surface station data was assimilated only in the SEN-SFC experiment, the 3D-VAR initial analysis tended to underestimate the lower atmospheric wind speed and the simulated results showed a weaker typhoon circulation. On the contrary, the sounding observations improved the initial atmospheric information below $500 \mathrm{hPa}$, thus the SEN-SND simulation results were slightly better than the SEN-SFC. Furthermore, in the SEN-DRV experiment, the 3D-VAR analysis showed the best wind speed profile result, particularly increasing the low level wind speed.

Figure 18 shows the typhoon's central SLP obtained from these sensitivity experiments for every hour from 0000 to 0600 UTC 25 August. Although the 3D-VAR analyses were quite different for horizontal wind in Fig. 16, the assimilation of different kinds of observational data did not lead to many adjustment differences of the typhoon's minimum SLP at simulation initial time 0000 UTC 25 August. However there were apparent differences in the consequent MM5 model forecast simulation. Assimilation of Doppler radial velocities had a significant impact (SEN-DRV, Circles) on the simulation results. In the 1-h simulation, the minimum SLP in SEN-DRV descended $2.6 \mathrm{hPa}$ from 983.8 to $981.2 \mathrm{hPa}$; the minimum SLP remained under $981 \mathrm{hPa}$ afterwards. In SEN-SND, the minimum SLP decreased $1 \mathrm{hPa}$ more than NON in the first hour of forecasting. Afterward, the impact of data assimilation on SLP prediction was not obvious in SEN-SFC. Its intensity was even weaker than SEN-NON during the last 3 hour simulation. On average, the 6-h predicted typhoon intensity increased about 3.0, 0.27 and $-0.18 \mathrm{hPa}$ for SEN-DRV, SEN-SND and SEN-SFC, respectively. The assimilation of surface data did not help to increase the typhoon intensity and even decreased it in this particular case. In contrast the SEN-DRV experiment resulted in better predictions of typhoon intensity and location. 


\section{SUMMARY}

Because approximately two-thirds of Taiwan is covered by mountains, the orographic effects are very important for affecting typhoon structure as well as generating and intensifying heavy rainfall during a typhoon invasion over Taiwan. Due to the complicated interaction of the typhoon circulation and the Central Mountain Range of Taiwan, forecasting the distribution and variation of wind and precipitation is very difficult for a typhoon event.

The main goal of this study is to investigate the possibility of using Doppler radial velocity assimilation with a 3D-VAR system to improve short-term predictions of typhoon events in Taiwan and the surrounding area. A series of experiments with Doppler radial velocity assimilation were carried out for Typhoon Aere during 24 - 25 August 2004. As the typhoon approached Taiwan, Doppler radial velocity assimilation helped to improve the typhoon predictions including the center location, circulation and intensity.
The accurate prediction of these three factors could improve the rainfall forecasting performance of the model.

The circulation around the typhoon eye wall was resolved in more detail by the RCWF Doppler radar when the typhoon moved closer to the northern part of Taiwan. The model predicted fields including sea level pressure, wind and precipitation were improved with the additional observed wind information through Doppler radial velocity assimilation. However, these improvements were not obvious when the typhoon was still far from the radar site and only part of its core area could be observed by the radar. In the meantime, the radar wind data assimilation caused the typhoon to deflect southward in the DRV and GAD experiments because of the limited and uneven radar data coverage. In another experiment in which Doppler radar data assimilation did not start until Typhoon Aere moved closer such that its entire core region could be observed, a similar track deflection was avoided. In the experiments without Doppler radial velocity assimilation (CTL and GTS), the simulated
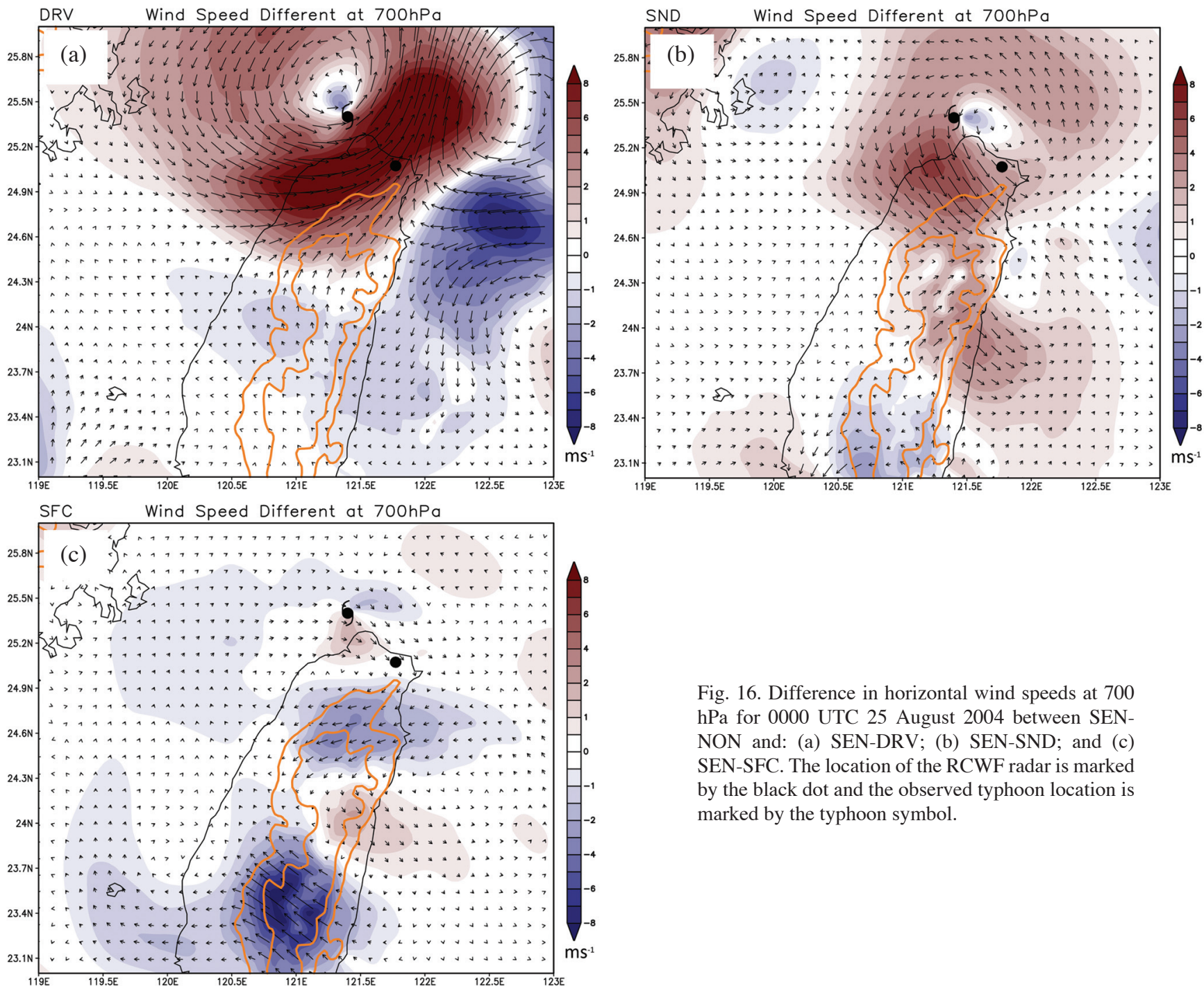

Fig. 16. Difference in horizontal wind speeds at 700 hPa for 0000 UTC 25 August 2004 between SENNON and: (a) SEN-DRV; (b) SEN-SND; and (c) SEN-SFC. The location of the RCWF radar is marked by the black dot and the observed typhoon location is marked by the typhoon symbol. 
typhoon center moved westward directly and didn't deflect to the south as in the results with radar data assimilation. Overall, the assimilation of Doppler wind data could reduce typhoon intensity forecasting errors by about $25 \%$. The assimilation with radar radial wind and GTS data (in GAD) showed that the GTS data was able to supplement the radar wind data and retrieved much better environmental flow, which led to improved typhoon track prediction. When the typhoon center moved closer to Taiwan and the whole circulation of the core region could be observed completely by the Doppler radar, the typhoon tracks were predicted more correctly with radar data assimilation in the DRV, GAD and RV3 experiments.

In addition to the improved typhoon track, the Doppler velocity data assimilation also caused more symmetric typhoon circulation than the GTS data assimilation and improved the wind distribution over the northern part of Taiwan. Moreover, the simulated reflectivity of the typhoon eye wall and rainband with Doppler wind data assimilation was much more similar to the observed radar reflectivity. The three-dimensional variational radar data assimilation constructed more corrected wind fields and improved the topographic lifting region on the windward slope of the Snow Mountain Range, which subsequently improved the model prediction of heavy rainfall distribution. The predicted rainfall amounts and precipitation regions with radar wind data assimilation were more accurate than the experiments without it as the typhoon approached the northern part of Taiwan. The Threat Score and BIAS calculation showed that the 3-h accumulated rainfall was better predicted through the aid of repeated assimilation cycles with Doppler velocity. There are many mesoscale convective systems (MCSs) embedded in typhoon rainbands due to the interaction be- tween typhoon circulation and the high mountain ranges of Taiwan, including SMR and CMR. The complex mesoscale wind and precipitation associated with these MCSs can be observed by radar. Through radar data assimilation, the improved mesoscale wind structures revealed in a mesoscale model can be used to improve the prediction of typhoon track and precipitation.

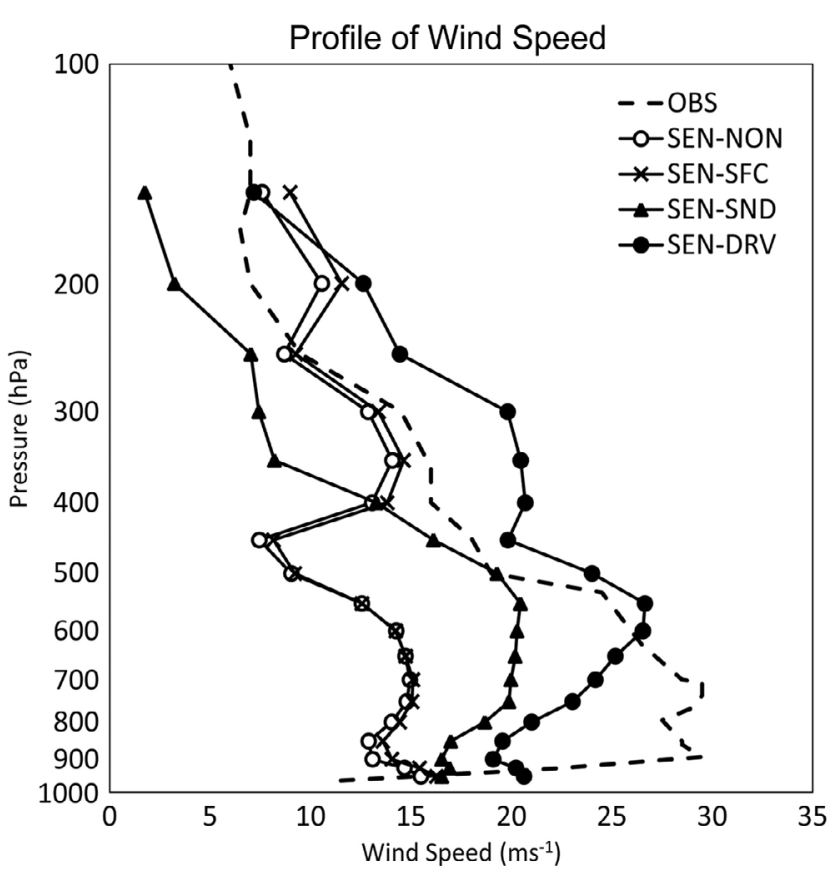

Fig. 17. Sounding profile of wind speed for each experiment including: (1) observation (dashed lines); (2) SEN-NON (stars); (3) SEN-SFC (crossed symbols); (4) SEN-SND (triangles); and (5) SEN-DRV (solid dots) at 0000 UTC 25 August 2004.

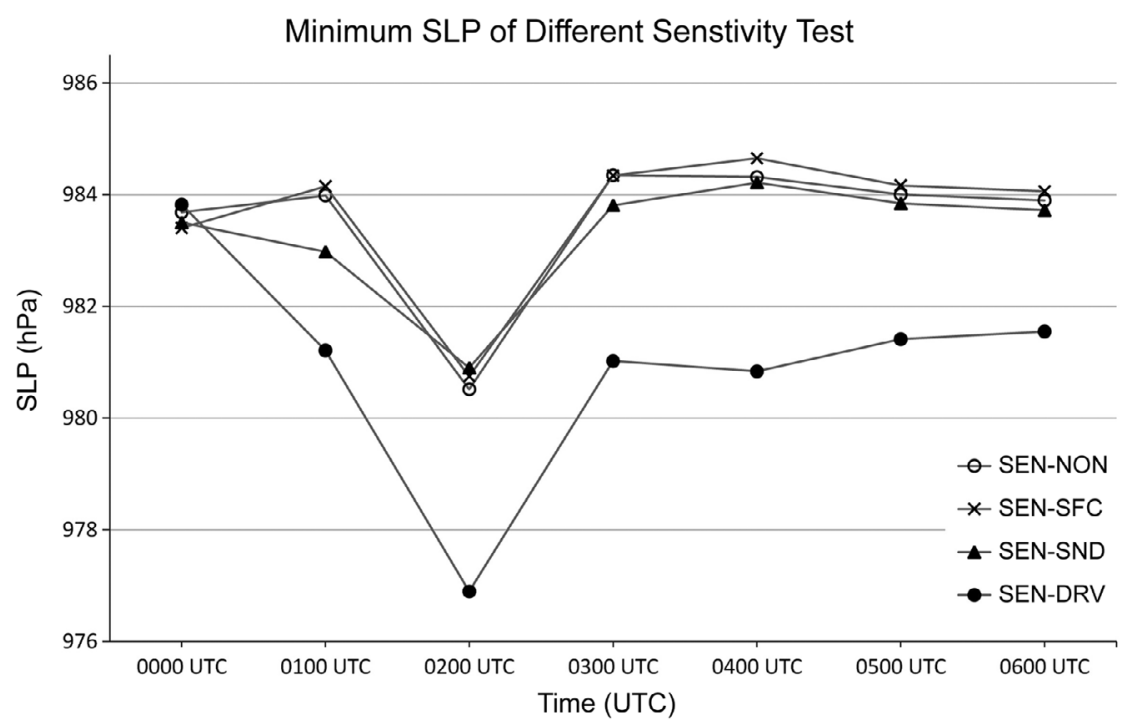

Fig. 18. Time variation of the simulated central sea-level pressure (hPa) for each experiment including: (1) SEN-NON (stars); (2) SEN-SFC (crossed symbols); (3) SEN-SND (triangles); and (4) SEN-DRV (solid dots). Times are in UTC on 25 August 2004. 
In order to distinguish the effects of the 3D-VAR data assimilation of traditional surface data, sounding data and radar radial wind data, several sensitivity experiments were conducted. The conventional routine observations couldn't describe the typhoon circulation patterns well due to insufficient resolution and the data void region over the ocean. Doppler radar has high spatial and temporal data density, covering a wide area over the ocean. It could make up for the lack of conventional observations. In the sensitivity tests, the assimilation of surface data decreased the typhoon intensity because the surface station data do not describe the typhoon vertical profiles of wind speed. The sparse upperlevel sounding data are unable to describe the typhoon's circulation structures in detail. Therefore, assimilating the conventional data alone was likely to lead to incorrect simulations of typhoon circulation. Alternately, the ingestion of radar radial wind data caused the typhoon center in 3D-VAR analysis to move closer toward the observation location. Compared to surface or upper-air sounding data, the assimilation of Doppler radial velocities show the most positive impact in the intensity of the typhoon, especially over the ocean where conventional data are sparse. More case studies are required in the future to support our findings.

Finally, in order to compensate the radar coverage limitation and extend predictable time, other types of observations should be assimilated into the model as well. Satellite observations such as GPS and QSCAT, are helpful and will improve typhoon forecasting, especially when typhoons are still over the ocean far from Taiwan, beyond radar coverage and where traditional observations are very sparse. Another valuable observation is dropsonde data that can offer typhoon environmental sounding profiles. However, the higher resolution of radar data becomes more important when typhoons move into radar scanning ranges. Doppler radar wind assimilation in a typhoon prediction model has already demonstrated improvement in this case study. More of these typhoon case studies and relative effects from different kinds of data sets are worthy subjects of investigation in the near future.

Acknowledgements This work was supported by the National Science Council of Taiwan under Grants NSC992111-M008-009, NSC99-2625-M-008-006, NSC95-2111M-008-036-AP1, NSC94-2111-M-008-011-AP1, and NSC 96-2752-M-008-006-PAE. Comments from Tai-Chi Chen Wang, Chung-Hsiung Sui, Fang-Yi Cheng, Yu-Chieng Liou and the reviewers are greatly appreciated. We thank the Central Weather Bureau, Taipei, Taiwan, for providing the radar data and the rain gauge data.

\section{REFERENCES}

Barker, D. M., W. Huang, Y. R. Guo, and A. Bourgeois, 2003: A three-dimensional variational (3DVAR) data assimilation system for use with MM5. NCAR Tech. Note, 68 pp.

Chen, S. H., 2007: The impact of assimilating SSM/I and QuikSCAT satellite winds on Hurricane Isidore simulations. Mon. Weather Rev., 135, 549-566, doi: 10.1175/ MWR3283.1. [Link]

Chen, S. Y., C. Y. Huang, Y. H. Kuo, Y. R. Guo, and S. Sokolovskiy, 2009: Assimilation of GPS refractivity from FORMOSAT-3/COSMIC using a nonlocal operator with WRF 3DVAR and its impact on the prediction of a typhoon event. Terr. Atmos. Ocean. Sci., 20, 133-154, doi: 10.3319/TAO.2007.11.29.01(F3C). [Link]

Chou, K. H. and C. C. Wu, 2008: Typhoon initialization in a mesoscale model - Combination of the bogused vortex and the dropwindsonde data in DOTSTAR. Mon. Weather Rev., 136, 865-879, doi: 10.1175/2007MWR 2141.1. [Link]

Gao, J. and M. Xue, 2008: An efficient dual-resolution approach for ensemble data assimilation and tests with simulated Doppler radar data. Mon. Weather Rev., 136, 945-963, doi: 10.1175/2007MWR2120.1. [Link]

Gao, J., M. Xue, A. Shapiro, and K. K. Droegemeier, 1999: A variational method for the analysis of threedimensional wind fields from two Doppler radars. Mon Weather Rev., 127, 2128-2142, doi: 10.1175/1520-049 3(1999)127<2128:AVMFTA >2.0.CO;2. [Link]

Grell, G. A., 1993: Prognostic evaluation of assumptions used by cumulus parameterizations. Mon. Weather Rev., 121, 764-787, doi: 10.1175/1520-0493(1993)121 $<0764$ :PEOAUB >2.0.CO;2. [Link]

Hong, S. Y. and H. L. Pan, 1996: Nonlocal boundary layer vertical diffusion in a medium-range forecast model. Mon. Weather Rev., 124, 2322-2339, doi: 10.1175/ 1520-0493(1996)124<2322:NBLVDI>2.0.CO;2. [Link]

Hu, M. and M. Xue, 2006: 3DVAR and cloud analysis with WSR-88D level-II data for the prediction of the Fort Worth, Texas, tornadic thunderstorms. Part II: Impact of radial velocity analysis via 3DVAR. Mon. Weather Rev., 134, 699-721, doi: 10.1175/MWR3093.1. [Link]

Jian, G. J., S. L, Shieh, and J. A. McGinley, 2003: Precipitation simulation associated with Typhoon Sinlaku (2002) in Taiwan area using the LAPS diabatic initialization for MM5. Terr. Atmos. Ocean. Sci., 14, 261288.

Lindskog, M., K. Salonen, H. Järviene, and D. B. Michelson, 2004: Doppler radar wind data assimilation with HIRLAM 3DVAR. Mon. Weather Rev., 132, 1081-1092, doi: 10.1175/1520-0493(2004)132<1081:DRWDAW> 2.0.CO;2. [Link]

Montmerle, T. and C. Faccani, 2009: Mesoscale assimilation of radial velocities from Doppler radars in a preoperational framework. Mon. Weather Rev., 137, 1939- 
1953, doi: 10.1175/2008MWR2725.1. [Link]

Reisner, J., R. M. Rasmussen, and R. T. Bruintjes, 1998: Explicit forecasting of supercooled liquid water in winter storms using the MM5 mesoscale model. Q. J. R. Meteorol. Soc., 124, 1071-1107, doi: 10.1002/qj.49712 454804. [Link]

Snyder, C. and F. Zhang, 2003: Assimilation of simulated Doppler radar observations with an Ensemble Kalman Filter. Mon. Weather Rev., 131, 1663-1677, doi: 10.11 75//2555.1. [Link]

Sun, J. and N. A. Crook, 1997: Dynamical and microphysical retrieval from Doppler radar observations using a cloud model and its adjoint. Part I: Model development and simulated data experiments. J. Atmos. Sci., 54, 1642-1661, doi: 10.1175/1520-0469(1997)054<16 42:DAMRFD $>2.0 . C O ; 2$. [Link]

Sun, J. and N. A. Crook, 1998: Dynamical and microphysical retrieval from Doppler radar observations using a cloud model and its adjoint. Part II: Retrieval experiments of an observed Florida convective storm. $J$. Atmos. Sci., 55, 835-852, doi: 10.1175/1520-0469(1998) 055<0835:DAMRFD >2.0.CO;2. [Link]

Tong, M. and M. Xue, 2005: Ensemble Kalman filter assimilation of Doppler radar data with a compressible nonhydrostatic model: OSS experiments. Mon. Weather Rev., 133, 1789-1807, doi: 10.1175/MWR2898.1. [Link]

Wu, C. C. and Y. H. Kuo, 1999: Typhoons affecting Taiwan: Current understanding and future challenges. Bull. Amer. Meteorol. Soc., 80, 67-80, doi: 10.1175/1520-04 77(1999)080<0067:TATCUA>2.0.CO;2. [Link]

Wu, C. C., K. H. Chou, Y. Wang, and Y. H. Kuo, 2006: Tropical cyclone initialization and prediction based on four-dimensional variational data assimilation. $J$. Atmos. Sci., 63, 2383-2395, doi: 10.1175/JAS3743.1. [Link]

Wu, C. C., K. H. Chou, P. H. Lin, S. D. Aberson, M. S. Peng, and T. Nakazawa, 2007: The impact of dropwindsonde data on typhoon track forecasts in DOTSTAR. Weather Forecast., 22, 1157-1176, doi: 10.1175/2007 WAF2006062.1. [Link]
Xiao, Q. and J. Sun, 2007: Multiple-radar data assimilation and short-range Quantitative Precipitation Forecasting of a squall line observed during IHOP_2002. Mon. Weather Rev., 135, 3381-3404, doi: 10.1175/MWR34 71.1. [Link]

Xiao, Q., Y. H. Kuo, J. Sun, W. C. Lee, E. Lim, Y. R. Guo, and D. M. Barker, 2005: Assimilation of Doppler radar observations with a regional 3DVAR system: Impact of Doppler velocities on forecasts of a heavy rainfall case. J. Appl. Meteorol. Climatol., 44, 768-788, doi: 10.1175/JAM2248.1. [Link]

Xiao, Q., Y. H. Kuo, J. Sun, W. C. Lee, D. M. Barker, and E. Lim, 2007: An approach of radar reflectivity data assimilation and its assessment with the inland QPF of Typhoon Rusa (2002) at landfall. J. Appl. Meteorol. Climatol., 46, 14-22, doi: 10.1175/JAM2439.1. [Link]

Xiao, Q., J. Sun, W. C. Lee, Y. H. Kuo, D. M. Barker, E. Lim, D. J. Won, M. S. Lee, W. J. Lee, J. Y. Cho, D. K. Lee, and H. S. Lee, 2008: Doppler radar data assimilation in KMA's operational forecasting. Bull. Amer. Meteorol. Soc., 89, 39-43, doi: 10.1175/BAMS-89-139. [Link]

Xue, M., M. Tong, and K. K. Droegemeier, 2006: An OSSE framework based on the Ensemble Square Root Kalman Filter for evaluating the impact of data from radar networks on thunderstorm analysis and forecasting. $J$. Atmos. Ocean. Technol., 23, 46-66, doi: 10.1175/JTE CH1835.1. [Link]

Zhang, F., C. Snyder, and J. Sun, 2004: Impacts of initial estimate and observation availability on convective-scale data assimilation with an ensemble Kalman filter. Mon. Weather Rev., 132, 1238-1253, doi: 10.1175/1520-049 3(2004)132<1238:IOIEAO>2.0.CO;2. [Link]

Zhao, Q. and Y. Jin, 2008: High-resolution radar data assimilation for hurricane Isabel (2003) at landfall. Bull. Amer. Meteorol. Soc., 89, 1355-1372, doi: 10.1175/20 08BAMS2562.1. [Link]

Zhao, Q., J. Cook, Q. Xu, and P. R. Harasti, 2006: Using radar wind observations to improve mesoscale numerical weather prediction. Weather Forecast., 21, 502-522, doi: 10.1175/WAF936.1. [Link] 